Maps, meanings and loanwords.

\title{
The interaction of geography and semantics in lexical borrowing
}

short title: Maps, meanings and loanwords

Karlien Franco (QLVL, University of Leuven)

Dirk Geeraerts (QLVL, University of Leuven)

Dirk Speelman (QLVL, University of Leuven)

Roeland van Hout (Radboud University Nijmegen)

Corresponding author:

\author{
Karlien Franco \\ University of Leuven \\ Department of Linguistics \\ Blijde-Inkomststraat 21 (PO box 3308) \\ 3000 Leuven \\ Belgium \\ karlien.franco@kuleuven.be \\ +321637 7954
}




\title{
Maps, meanings and loanwords.
}

\section{The interaction of geography and semantics in lexical borrowing}

\begin{abstract}
The use of loanwords is generally attributed to a social feature, like social prestige, and to semantic features, like the need to fill a lexical gap. However, few studies take into account variation in the use of loanwords within a speech community, and directly compare the frequency of loanwords from more than one source language. This paper contributes to research on lexical borrowing by comparing the distribution of loanwords from three different source languages in two large databases of dialect data. We take an onomasiological perspective, which allows us to gauge the frequency of borrowed lexical items vis-à-vis alternative expressions. Using Generalized Additive Mixed Modelling, we show that the usage of loanwords can only be explained by taking into account the interaction between semantics and geographical diffusion. Our analysis confirms that the patterns that occur almost exclusively reflect changes in socio-cultural history.
\end{abstract}

Acknowledgments

This research was supported by the Research Foundation Flanders (FWO, grant no. G042114N). 


\section{INTRODUCTION}

Why and when do language users rely on loanwords? (Lexical) borrowing is often explained by means of an interaction between the social prestige of the language varieties involved and semantic properties of the concept to be expressed (e.g. Hock \& Joseph, 1996; McMahon, 1994; Thomasson \& Kaufman, 1991; Winford, 2010). More specifically, the presence of loanwords in a particular receptor language is generally analysed by referring to the necessity to express a particular concept for which no native equivalent exists (e.g. when a novel concept, like COMPUTER ${ }^{1}$, is introduced), or to the influence of a particular prestigious culture on domains of everyday life (e.g. the use of French words in English after the Norman conquest). One of the results of the Loanword Typology Project (Haspelmath \& Tadmor, 2009), for instance, is that the amount of loanwords that are borrowed in the world's languages, differs dramatically per semantic field (Tadmor, 2009: 64-65). Table 1 shows the distribution of loanwords per semantic field across the languages included in the project. Fields that are prone to borrowing across varieties include 'religion \& belief' (41.2\% loanwords), 'clothing and grooming' (38.6\% loanwords) and 'the house' (37.2\% loanwords), while only very few instances of lexical borrowing occur in the field of 'sense perception' (11\% loanwords), 'spatial relations' (14\% loanwords) and 'the body' (14.2\% loanwords). According to Tadmor, this has to do with the fact that the former fields are more heavily influenced by cultural interactions. The latter semantic fields consist of concepts that are not prone to borrowing as they contain a larger amount of core vocabulary, for which native elements are already available (cf. Swadesh 1955).

Table 1: Borrowing per semantic field in the Loanword Typology Project (Tadmor, 2009: 64)

\section{[insert table 1 about here]}

However, research on lexical borrowing does not frequently comprehensively take into account lectal variation within a speech community. Although Paul (1891[1880]: §698) already asserts that loanword

\footnotetext{
${ }^{1}$ In this paper, we use SMALLCAPS to refer to concepts. Italics are used for the words to express these concepts.
} 
usage can be prone to lectal variation, as the use of non-native material can be restricted to particular groups, connected by social ties or characterized by geographical proximity, an onomasiological perspective on the lectal dimension of lexical borrowing has only recently been receiving more attention (Zenner \& Kristiansen, 2014). More specifically, although earlier studies have paid attention to social or geographical correlates of variation in lexical borrowing (e.g. Poplack, Sankoff \& Miller, 1988, also see Kruijsen, 1995 and Weijnen, 1967 for loanwords in the dialects of Dutch), most research does not examine the distribution of loanwords from an onomasiological perspective, whereby the success of nonnative variants vis-à-vis their native alternatives that express the same meaning, is taken into account (an exception is Zenner, Speelman \& Geeraerts, 2012). Additionally, hardly any studies provide a comprehensive comparative account of the influence of different prestigious cultures on a particular receptor language by examining borrowings from more than one source language in a single dataset of naturalistic material (for Dutch, notable exceptions include Geeraerts, Grondelaers \& Speelman, 1999 and Daems, Heylen \& Geeraerts, 2015; Van der Sijs, 2005 brings together previous research on loanwords from different source languages that occur in Dutch). Consequently, although lectal and semantic features have been acknowledged as influential for the use of loanwords, and although recent approaches have argued that multifactorial, large-scale and mixed-data approaches can further inform the process of (lexical) borrowing (Zenner \& Kristiansen, 2014: 10), research that examines the interaction between semantics and lectal variation for different sources languages at once in a systematic and quantitative way, is lacking.

This paper aims to fill this gap by focusing on the use of loanwords from three different source languages in a large dataset of dialect data. More specifically, it contributes to research on lexical borrowing in four ways. First, it ensures an onomasiological perspective. As argued in the Cognitive Sociolinguistics paradigm, an onomasiological perspective is necessary to examine which factors govern the choice of a particular lexical item, like a loanword, instead of an equivalent expression, to convey a particular meaning (Geeraerts, Kristiansen \& Peirsman, 2010; Kristiansen \& Dirven, 2008; Zenner \& 
Kristiansen, 2014). Second, it explicitly acknowledges that the distribution of borrowed material may be variable within a speech community. We examine the influence of lectal differences by inquiring into the geographical distribution of the borrowed lexemes. Third, it examines the use of loanwords in different semantic fields, which allows us to gauge the extent to which the interaction between the lectal feature, geography, and semantic features influences the use of non-native material. Fourth, it uses an inferential technique, Generalized Additive Mixed Modelling, and a large dataset to gauge variation in the use of loanwords. Consequently, we can establish that the patterns that are found are robust and cannot be attributed to chance.

In practice, we analyse the distribution of loanwords from three different source languages that occur in the Brabantic and Limburgish dialects of Dutch. We rely on large databases of naturalistic and geographically stratified dialect data, which form the source material for two onomasiological dialect dictionaries of Dutch, viz. the Woordenboek van de Brabantse Dialecten 'Dictionary of the Brabantic Dialects' (WBD) and the Woordenboek van de Limburgse Dialecten 'Dictionary of the Limburgish Dialects' (WLD). By including four different semantic fields in the analysis, we examine the interaction between semantics and geographical variation. In the following section, we first provide an overview of the relationship between the Brabantic and Limburgish dialect areas and other languages and varieties. Then, we discuss the cultural patterns that have been shown to be relevant for the use of loanwords in Standard Dutch. In section 3, the hypotheses that can be distinguished on the basis of these patterns are outlined. Section 4 describes the data and methodology used in this paper. In section 5, the results of the analyses are presented, followed by a discussion in section 6 .

\section{LEXICAL BORROWING IN THE DUTCH LANGUAGE AREA}

\subsection{Geography and Cultural History}

Figure 1 is a map of Belgium and the Netherlands that shows the location of the Brabantic and Limburgish dialect areas. It also shows the province borders within these dialect regions. The Brabantic 
dialect area (in orange) consists of the province of North Brabant (N. Brabant) in the Netherlands and of the provinces of Antwerp, Flemish Brabant (Fl. Brab.), and the Brussels area in Belgium. In the Belgian and Netherlandic provinces of Limburg (in purple), Limburgish dialects are spoken, as well as in a small area in the north of the province of Liège.

\section{[insert Figure 1 about here]}

Figure 1: The Brabantic and Limburgish dialect areas

Geographically, the two dialect areas are demarcated by the state border with Germany in the east and by the Germanic-Romance border in the south (in blue). In the northern part of Belgium, above the Germanic-Romance border, Dutch is spoken, whereas south of the border, French is used. The state border between Belgium and the Netherlands runs through the dialect areas as well (in red). As a result, two processes can be distinguished that may influence variation in the use of non-native lexical items in these dialects. First, we may expect to find border effects, as language contact between varieties that are geographically nearby can cause interference between the varieties: the closer to the border, the larger the expected amount of loanwords from the nearby language. Second, previous research has shown that state borders can evolve into language borders (Hinskens, Kallen \& Taeldeman, 2000). Crucially, the cultural history of the northern, Dutch-speaking part of Belgium and that of the Netherlands is not identical (an overview of the history of the Dutch language situation can be found in Janssens \& Marynissen, 2008; Van der Wal \& Van Bree, 2008 and Willemeyns 2013). More specifically, throughout western European history, several diglossic constellations have been relevant, in which a particular exoglossic standard exerted its influence on everyday language (Auer, 2005). However, due to the different socio-political history of Belgium and the Netherlands, the diglossic constellation of the northern part of Belgium has differed from the Netherlandic one.

The following paragraphs provide an overview of the expected influence of French, Latin and German on the Brabantic and Limburgish dialects. Although loanwords from other languages occur in the WBD 
and WLD as well, they are too infrequent to be included in the analysis, probably because the databases contain concepts concerning the everyday life of dialect speakers in the traditional agrarian society. In total, only 93 borrowed word types from other source languages occur. The number of loanword types from French is 1644, from Latin 319 and from German 589.

\subsubsection{French}

According to Van der Sijs (2005), due to a long history of contact with the French people, French loanwords are, overall, widely accepted in Standard Dutch and they occur in a variety of semantic fields, including military (e.g. artillerie 'artillery' and luitenant 'lieutenant'), the arts (e.g. melodie 'melody' and gravure 'engraving') and everyday language (e.g. fauteuil 'armchair' and blouse 'shirt'). Furthermore, French loanwords are frequently used in Dutch for concepts relating to administration and government, which can be explained by the fact that French administration and law were introduced in the Low Countries during the Napoleontic regime (1795-1813). Additionally, French was used for these purposes even longer in the northern part of Belgium, until the Flemish movement gained political ground and Dutch became the official language of politics, education and administration in the 1930s. Daems et al. (2015) and Geeraerts et al. (1999) inquire into the use of French for a semantic field pertaining to everyday language, viz. clothing concepts (also see Van der Sijs, 2005: 184). They clearly find diverging patterns between the northern part of Belgium and the Netherlands. More specifically, French occurs more frequently in Belgian Dutch than in Netherlandic Dutch. However, due to its complex relationship with the French culture, Belgian Dutch seems to react, in a purist fashion, against the abundance of French loanwords in the language, which is apparent from the decreasing number of French loanwords between the 1950s and 2012 in the field of clothing terminology. A similar defensive tendency is absent in Netherlandic Dutch.

Additionally, research on lexical borrowing has indicated that, in the Hesbaye dialects of Dutch located near the Germanic-Romance border, the distance hypothesis holds (Kruijsen, 1990): the further away from the border, the smaller the amount of borrowings from French. However, as the language border only 
became a political border in the 1960s, the amount of French items used by a speaker is also dependent on their age and on the amount of contact they have with francophones (Van Hout, Kruijsen \& Gerritsen, 2014).

Finally, in the south of the Brabantic dialect area, the bilingual city of Brussels is located. This city, which is the capital of Belgium, was frenchified to a much larger extent than other large cities in the northern part of Belgium due to socio-political developments (Willemyns, 2008: 24-25). Although initially French only served as the language of the nobility, the number of people who used a variety of Dutch decayed over time, in favour of the French language (De Vriendt, 2004: 20-29 and 91-94).

\subsubsection{Latin}

Latin has exerted its influence on Standard Dutch in various domains and throughout time (Van Keymeulen, 2008; Weijnen, 1976). Van der Sijs \& Engelsman (2000) mention the influence of Latin on the Germanic languages during the Roman era in semantic fields like military and politics (e.g. defensie 'military defense' and pijl 'arrow'), trade (e.g. munt 'coin' and kopen 'to buy') and the names for days of the week and for the months. In medieval times, Latin was mostly important as the language of the Catholic church but it also exerted its influence on Dutch for concepts relating to education (e.g. school 'school' and schrijven 'to write'), science (epidemie 'epidemic' and recept 'recipee'), and for administration and government (artikel 'article' and decreet 'decree'). Furthermore, words from Church Latin were borrowed for novel religious concepts when the people of the Low Countries were christened (Van der Sijs, 2005: 124). Semantic fields that were influenced by Latin during the Renaissance period, finally, include the field of higher education (e.g. academie 'academy' and docent 'university teacher') and administration and government (e.g. agenda 'calendar' and collega 'colleague'). Crucially, in comparison to French, the use of Latin is probably less prone to geographical variability, as Latin has predominantly been influential as a written, academic language. Political conflicts between the Germanic tribes and Roman people, who spoke a variety of Latin as their native tongue, only occurred in the Roman era. 


\subsubsection{German}

According to Van der Sijs (2005: 257-259; also see Weinreich, 1968: 1-2), the fact that German and Dutch are closely related languages, results in a smaller amount of loanwords that are clearly German in Standard Dutch, because they are often borrowed in a "dutchified" form (e.g. bespreken 'to dicuss' from German besprechen, drukknoop 'press-stud' from German Druckknopf and warenhuis 'department store' from German Warenhaus). Furthermore, although the German language area shares a border with the region where Dutch is spoken, the influence of French has always been larger, because of the great importance of French culture throughout Europe since the Middle Ages (Van der Sijs, 2005: 268). In Standard Dutch, the semantic fields in which the influence of the German language and culture are clear, are trade, religion, science and warfare (Van der Sijs, 2005: 274-286). Trade terminology was predominantly borrowed through trade contacts with the Hanse in the Middle Ages. As a result, the Dutch language contains Middle Low German words like eigenwijs 'precocious', daalder 'thaler' and kroeg 'pub'. After the Middle Ages, High German became the dominant variety. Many religious loanwords stem from after the Reformation, when the Luther Bible was translated from (High) German into Dutch, like afvallig 'unfaithful', heftig 'fierce, intense' and slachtoffer 'victim'. In the $19^{\text {th }}$ century, German culture was influential in areas like science (e.g. bewusteloos 'unconscious', psychoanalyse 'psychoanalysis' and volksetymology 'folk etymology'), socialism and politics (e.g. jeugdbeweging 'youth movement', kartel 'cartel' and autobaan 'motorway') and industry (erts 'ore', benzine 'petrol' and Fahrenheit). Finally, German words in Dutch having to do with warfare and army are schermutselen 'to skirmish', hamsteren 'to hoard' and concentratiekamp 'concentration camp'.

In the east of the province of Limburg, a border with Germany is found, which was installed at the beginning of the $19^{\text {th }}$ century. This border is interesting as German and Dutch are closely related WestGermanic languages. More specifically, the Germanic and Dutch dialects historically form a continuum: some of the dialects spoken in the south of Limburg in the Netherlands can even be considered dialects of German, as they underwent the second Germanic consonant shift (viz. the Ripuarian dialects, see Van de 
Wijngaard and Keulen, 2007). Research into the effect of the border with Germany in the Kleverland dialect continuum in the north of Netherlandic Limburg has shown that it has come to serve as a social and linguistic boundary and that the dialects on each side of the border show signs of convergence with their respective standard varieties (De Vriend, Giesbers, Van Hout \& Ten Bosch, 2014; Giesbers, 2008). The extent to which the Ripuarian dialects have been influenced by the language border has been less systematically researched (but see Cornelissen, 2007 for an overview of relatively recent loanwords from German).

\subsection{Hypotheses}

To investigate the interaction between semantics and geography on variation in the use of loanwords in the Brabantic and Limburgish dialects, we focus on four volumes (i.e. semantic fields) of the digitized databases of the WBD and WLD:

- $\quad$ III.1.3: clothing \& personal hygiene

- $\quad$ III.1.4: personality \& feelings

- III.3.1: society, school \& education

- III.3.3: church \& religion

As will be discussed in more detail below, these semantic fields were chosen because they are expected to show clear patterns of geographical and cultural variation in the use of loanwords. Furthermore, while most of the fields are prone to borrowing according to Tadmor (2009), the field of personality \& feelings takes up a special place. ${ }^{2}$

As outlined above, concepts from the semantic field of clothing \& personal hygiene, are part of the everyday language of a dialect speaker and are prone to lexical borrowing (38.6\% borrowed items in

\footnotetext{
${ }^{2}$ It should be noted that the semantic fields distinguished by Haspelmath and Tadmor are not identical to the semantic fields in the WLD and WBD, nor do they contain exactly the same concepts. However, as both were collected on a very large scale, we assume that the general patterns are comparable.
} 
Tadmor, 2009). Additionally, detailed research into this field has shown that the use of French loanwords is especially frequent, although clear differences between Belgian and Netherlandic Dutch occur (Daems et al., 2015; Geeraerts et al., 1999). As the dialectal data we use come from an early time period ( $87.5 \%$ of the clothing data in the database were collected in the 1960s) and from a different variety (viz. from the base dialects of Dutch), our data serve as a historical, differently stratified alternative to the oldest data used in Geeraerts et al. (1999).

In the semantic field of society, school \& education, lexical borrowings from both French and German are expected. Table 2 shows the subdomains in this field in the WLD. ${ }^{3}$ On the one hand, it contains concepts relating to the military, politics and education, which have been argued to often be expressed with French items. Additionally, as French culture was dominant for a longer period in the northern part of Belgium, in this field, we expect to find differences between Belgium and the Netherlands. On the other hand, trade and industry concepts, which can be related to German culture, are included as well. In as far as this field is included in Tadmor's division, it is expected to show a relatively high amount of loanwords as well (law: $34.3 \%$ loanwords, social and political relations: $31.0 \%$ loanwords, warfare and hunting: 27.9\% loanwords, possession: $27.1 \%$ loanwords, speech and language: $22.3 \%$ loanwords).

Table 2: Subdomains of the field of society, school \& education in the WLD

\section{[insert table 2 about here]}

The field of church \& religion is chosen because, according to Tadmor (2009), this field is highly susceptible to borrowing. The use of Latin lexical borrowings is expected to be especially frequent in this field, although some German loanwords may be used as well. However, we expect to find no geographical variation for the distribution of loanwords in this field, as the concepts in the database refer to practices in the Catholic church, which were frequent throughout Limburg and Brabant (Schmeets, 2014). Additionally, many of the church-related Latin words were introduced as names for novel concepts.

\footnotetext{
${ }^{3}$ The subdivision into subdomains is almost identical in the WLD and WBD across dictionary chapters.
} 
Finally, we also include the semantic field of personality $\&$ feelings. Table 3 shows the subdomains of this semantic field in the WLD. On the one hand, this table contains some concepts, relating to feelings/emotions and values, that are not prone to borrowing according to Tadmor (2009, see Table 1), because they contain universal/core vocabulary concepts. On the other hand, some subsections of this semantic field, like behavioural traits or affect-sensitive concepts (e.g. concepts related to indecency or stupidity), may also require a certain degree of personal involvement. As a result, if we do find a large number of loanwords in this field, perhaps this has to do with the "need for synonyms" of the speakers, which allows them to retain the expressive force of affect-laden concepts (Weinreich, 1968: 58-59). However, if we do not find that loanwords are used for personality \& feelings concepts, we can provide further evidence for the universal stability of some semantic domains.

Table 3: Subsections of the field of personality \& feelings in the WLD

[insert table 3 about here]

In sum, a complex interaction between semantic and geographical features is expected to influence variation in the use of French, Latin and German loanwords in the Brabantic and Limburgish dialects of Dutch. First, expansional border effects are expected to show up near the border with Germany and near the Germanic-Romance language border in the semantic fields that are assumed to be prone to borrowing. Furthermore, French is also expected to be more frequent around the city of Brussels, where it holds a stronger position than in the rest of the language area. Second, cultural contact will probably show up as well, through the influence of an exoglossic standard on particular semantic fields. Such cultural effects are predominantly expected for French, especially for concepts relating to society, school \& education and clothing \& personal hygiene, and for Latin, in the field of church \& religion, although German items may be used for concepts relating to these fields as well. However, differences in the geographical distribution between the former two exoglossic standards can also show up. In the use of Latin and German for church concepts, no geographical patterns are expected, as most of these loanwords were probably introduced as names for novel, institutionalized concepts, both in Standard Dutch and in the base dialects. For French, in 
contrast, we do expect geographical differences. The French culture held a stronger position in Belgium than in the Netherlands, which may result in geographical variation between the countries. These differences will probably be especially relevant in the semantic field of society, school \& education, which contains institutionalized concepts relating to administration and politics. On the other hand, the importance of French culture on everyday life will most likely show up in the field of clothing \& personal hygiene: we also expect to find differences between Belgium and the Netherlands here. The hypotheses are summarized per semantic field and per source language in Table 4.

Table 4: Overview of hypotheses in relation to the semantic fields

[insert table 4 about here]

\section{DATA AND METHODOLOGY}

3.1 Measuring the Amount of Loanwords per Location

The data used in this paper come from the digitized databases that form the source material for two large-scale dialect dictionaries of Dutch, viz. the Woordenboek van de Brabantse dialecten 'Dictionary of the Brabantic Dialects' (WBD) and the Woordenboek van de Limburgse dialecten 'Dictionary of the Limburgish Dialects' (WLD). These dictionaries are onomasiological dictionaries, which contain all the lexical dialect variants available for a large number of concepts throughout the Brabantic and Limburgish dialect areas. The databases consist of several volumes, with each volume representing one semantic field. We restrict attention to the dialectal data in the databases that were collected by means of questionnaires distributed throughout the Brabantic and Limburgish dialect area to ensure that the data were collected similarly and systematically, so that the relative frequency of loanwords vis-à-vis other lexical variants can be taken into account. ${ }^{4}$

\footnotetext{
${ }^{4}$ Other data that are available in the WBD include lexical items elicited by means of questionnaires distributed on a smaller geographical scale, or data collected from local dictionaries. These data are excluded from the analysis.
} 
Table 5: Example of the relevant columns from the semantic field of clothing \& personal hygiene in the WBD

[insert table 5 about here]

Table 5 shows an example of the relevant columns of the databases, from the semantic field of clothing \& personal hygiene in the WBD for the concepts ARMBAND 'bracelet' and BORSTROK 'undervest'. In total, the Brabantic dataset contains 153 and 1046 observations for these concepts, respectively. The first column shows the concept for which information is available. The second column contains the lexical variant, a dutchified form of the dialect response of a respondent. In the third column, the number of the questionnaire that was used to elicit this response is provided and in the final column, the location where the lexical variant was elicited, is presented. For some locations, more than one response is available. Crucially, the databases contain loanword tags, like 'fr.', 'du.' or 'lat.', which were added manually by the lexicographers, to indicate whether a particular (dutchified) lexeme for a concept has a non-native origin. ${ }^{5}$ For instance, the word bracelet for the concept ARMBAND is marked as French. This allows us to calculate automatically how frequently a variant from French, Latin or German is used. Table 6 contains example loanwords from every semantic field for every source language.

Table 6: Examples of loanwords per source language and semantic field

\section{[insert table 6 about here]}

We used the loanword tags in the dictionaries to automatically collect the number of native and nonnative French, German and Latin tokens per location and per semantic field. For instance, when focussing on the French terms, the Latin and German lexical items are considered as native (i.e. not French). The same procedure is used for the other source languages. In a few cases, lexical items that were marked as

\footnotetext{
${ }^{5}$ We consider lexical items marked as Picardic, Old French or Walloon as loanwords from French and lexemes marked as Ripuarian as loanwords from German. Overall, only 14 types (100 tokens) from Ripuarian, 13 from Old French (261 tokens), 2 from Walloon (6 tokens) and 1 from Picardic (1 token) occur. Two lexical items, proces for PROCES-VERBAAL 'report of an offence' (43 tokens) and tribunaal for KANTONGERECHT 'cantonal court' (20 tokens), are marked as French and Latin. We considered these word types as Latin loanwords, as they are both borrowed from Latin via French (Philippa et al. 2003-2009).
} 
non-native in the Limburgish data were not given a loanword tag in the Brabantic data and vice-versa. For example, the lexical variant zich ambeteren for ZICH VERVELEN 'to be bored' is marked as French in the Limburgish data, while it does not have a loanword tag in the WBD. To ensure maximal comparability between the dictionaries, we used an automatic tagging procedure to ensure that every variant that is labelled as French, Latin or German in one dictionary, has the same tag in the other dictionary.

The onomasiological perspective is safeguarded because our calculation relies on the frequency of nonnative variants for a set of concepts per semantic field, for which lexical variants were elicited throughout each dialect area. Additionally, for most of the locations, we only have one or two observations per concept at our disposal $($ mean $=1.417, \mathrm{sd}=0.561)$. Only two larger towns have, on average, more than 5 observations per concept, namely Maastricht $($ mean $=8.987, \mathrm{sd}=5.880)$ and Tilburg $($ mean $=5.053, \mathrm{sd}=$ 4.935).

Table 7 provides an overview of the total number of French, Latin and German tokens in the semantic fields that were included per dictionary, and the proportion of these non-native tokens per dictionary. Clearly, the overall proportion of French is much higher than the proportion of Latin and German. Interestingly, the proportion of French is also almost identical in the Brabantic and Limburgish data, while both Latin and German occur more frequently in Limburg. The full datasets, which show the amount of French, Latin and German per location, are available in the supplementary materials. ${ }^{6}$

Table 7: Absolute and relative number of French, Latin and German tokens per dictionary [insert table 7 about here]

\footnotetext{
${ }^{6}$ These datasets are based on an offline copy of the original dictionary data. The dictionary data are also available online at e-wld.nl and e-wbd.nl (available from 14 December 2017 onwards). We only include the data that were collected by systematically distributed questionnaires by the Centre for Dialectology and Onomastics in Nijmegen (cf. Franco, 2017: chapter 2 for a detailed description of the data).
} 


\subsection{Generalized Additive Modelling}

To measure the effect of the interaction between semantic field and geography on variation in the amount of French, Latin or German per location, we use Generalized Additive Mixed Modelling (GAMM). These models can be considered an extension of Generalized Linear Models that allow for a combination of parametric and non-parametric relationships, which do not have to be specified a priori, between the response and the explanatory variables (Wood, 2006; see Zuur et al., 2009 and Crawley, 2007, chapter 18 for an accessible introduction). More specifically, they employ non-parametric smooth functions on specified model terms as part of the model fitting procedure. The models we discuss below use thin-plate regression splines to represent these smooth terms. The amount of smoothing depends on a type of cross-validation, which in practice entails that the model finds the optimal amount of smoothing while avoiding badness of fit.

All the analyses were carried out with R (R Core Team, 2018). We build one model per source language. For each source language, we start from the same model to compare the influence of the interaction between geography and semantic field on variation in the amount of loanwords per location. The response variable is the ratio between the number of French, Latin, or German tokens and the number of native tokens per location. The model contains a smooth term for the interaction between longitude ${ }^{7}$ and latitude for each semantic field, and a random intercept for location, as the total number of observations differs per location (although this factor does not reach significance in the model for the Latin variants). In our model fitting procedure, we follow the suggestions of Crawley (2007: chapter 19), Van Rij (2015), Wieling $(2017,2018)$ and Wood (2006: 221 - 233) and outlined in the mgcv vignette (Wood, 2017). We compare AIC values and use significance tests to check whether all the predictor variables, interaction effects and smooth terms contribute to the explanatory power of the models. Finally, we visualize the predicted and the fitted values, and the residuals to assess the fit of the model to the data.

\footnotetext{
${ }^{7}$ We collected longitude and latitude information semi-automatically, using the Google Maps API (see https://www.r-bloggers.com/using-google-maps-api-and-r/, Accessed on 3 July 2017).
} 
The R-code that was used to conduct the analyses and the datasets are available in the supplementary materials.

\section{RESULTS}

Figures 2a-c are maps of the Limburgish and Brabantic dialect areas that show the distribution of the proportion of borrowed lexical items in the raw data per source language in the form of bubble plots. ${ }^{8}$ The plots are interactive: clicking on a black or red dot reveals the precise proportion of French, Latin or German tokens in the specific location. The size of the black symbols is proportionate to the variable under scrutiny (viz. the proportion of French, Latin, or German tokens per location). Black dots indicate that one or more loanwords were found. The larger the black dot, the more loanwords occur in that location. If a red dot is shown, this means that, while data for this location are available in the dictionaries, they do not contain any non-native tokens.

\section{[insert Figure 2 about here]}

Figure 2: Proportion of French (2a), German (2b) and Latin (2c) tokens per location

Figures 2a-c indicate that, overall, French loanwords are much more frequent than lexical items from the other source languages. Furthermore, the figures show clear geographical patterns. French is more frequent near the Germanic-Romance language border in Belgium, and in the Dutch-speaking part of Belgium in general. German occurs the most near the border with Germany, and specifically in the south of Limburg in the Netherlands. Loanwords from this language are especially frequent in three locations near the Dutch-German border (viz. in Simpelveld, Vaals and Kerkrade, which all belong to the Ripuarian dialect area). Unexpectedly, the distribution of the Latin tokens does show a geographical pattern: they occur the most in the Limburgish provinces, especially in the Netherlands. The following sections aim to

\footnotetext{
${ }^{8}$ The maps are OpenStreetMaps (OpenStreetMap contributors, Accessed on 20 December 2018) that were constructed with the leaflet package in R. The R-code that was used to create the maps is included in the supplementary materials.
} 
explain the patterns of variation in these bubble plots on the basis of the interaction between geography and semantics.

\subsection{French Loanwords}

Using the formula described above, with an interaction between longitude and latitude by semantic field and a random effect for location, we constructed a Generalized Additive Mixed Model. All the variables that were included in the model reach significance (the numerical output of the GAMM is included in Appendix 1A). Overall, the model performs well. It explains $92 \%$ of the null deviance. Adjusted $\mathrm{R}^{2}$, a value that ranges from 0 to 1 and that is another estimate for the amount of variation explained, is high as well: 0.908 . We also used diagnostic plots to verify that the assumptions of the model were met. ${ }^{9}$

\section{[insert Figure 3 about here]}

Figure 3: French tokens per location per semantic field

Figures 3a-d show the visual output of the GAMM, with the predicted surface for each semantic field presented in a separate panel. In each panel, the Brabantic and Limburgish dialect areas are depicted, with province and country borders indicated in black. A continuous colour scale is plotted over this geographical area, with yellow hues indicating that the ratio of French to non-French tokens is high and red hues indicating that the amount of French tokens is lower. In areas where the predicted amount of French tokens is smaller than 0.03 (the lower bound of the continuous colour scale), the plots show no colour. The colours used in this figure, as well as in the other figures in this paper, require some further attention. First, it is important to note that stronger, darker colour hues (the reddish ones) indicate a smaller amount of non-native tokens. Additionally, white regions can indicate that no borrowed lexemes

\footnotetext{
${ }^{9}$ More specifically, we verified that there is no harmful structure in the residuals (i.e. homoscedasticity), that the residuals are normally distributed, that there is a linear relationship between the predicted and observed values of the response variable and that a sufficient number of basis dimensions was used to construct the model.
} 
are available; in this case, the white areas are demarcated from the rest of the plot with non-smooth, jagged boundaries (like in Figures 3a, b and c). However, very pale hues of yellow may resemble white as well, although these light hues indicate that the amount of non-native tokens is very large. Crucially, in the latter case, smooth transitions rather than discontinuous borders are shown on the plots (like at the bottom of Figure 3d). The numerical interpretation of the colour scheme is provided in the legend at the top left of each panel. The legends and colour schemes are kept stable for each map per source language to ensure comparability across semantic fields. The minimum and maximum values for the legend are based on the predicted values for the semantic field where French occurs the most, viz. clothing \& personal hygiene. Additionally, the plots also show a number of green lines that run throughout the dialect areas. These lines can be interpreted as isoglosses.

The figures confirm that, as expected, the amount of French tokens is very high in the semantic field of clothing \& personal hygiene. French occurs even more often in this field than in the field of society, school \& education. This is surprising, because military, politics and education-related terms have often been mentioned as prime candidates for the use of French loanwords. Additionally, the geographical patterns on the maps for society, school \& education, on the one hand, and clothing $\&$ personal hygiene, on the other, are not identical, although both maps show clear patterns of geographical diffusion. For society-related concepts, the amount of French is high in Belgium, and in the province of Limburg in the Netherlands. The map for clothing terminology clearly demarcates Belgium from all the Netherlandic provinces. French tokens are less frequent in the field of church \& religion. The isoglosses, which do not show a large amount of smoothing in this field, seem to indicate that the larger the geographical distance from the city of Brussels, where French has always held a strong position, the smaller the predicted amount of French. The map for the semantic field 'personality \& feelings' also shows the effect of the bilingual city of Brussels. Additionally, a language border effect seems to show up near the border with 
Wallonia, the Germanic-Romance border. However, overall, the amount of French is very small in this field. ${ }^{10}$

In sum, two types of diffusion patterns are apparent. On the one hand, the country where a dialect speaker lives, impacts their usage of French loanwords to a large extent: French is used much more frequently in Belgium than in the Netherlands. The effect is so strong that the isoglosses on the map for the clothing concepts even seem to follow the state border between Belgium and the Netherlands. Additionally, the further away from the Germanic-Romance border and from the bilingual city of Brussels, the smaller the amount of French that is used. The maps, thus, seem to confirm a wave pattern of loanword diffusion, which is further reinforced by repeated exposure to French within the Belgian state border.

\subsection{Latin Loanwords}

To determine the influence of semantic field and geography on variation in the use of loanwords from Latin, the same model formula was used, with an interaction between longitude and latitude by semantic field and a random effect for location. However, the random effect for location did not reach significance and was therefore removed from the model (see Appendix 1B). Additionally, the smooth term for clothing $\&$ personality did not differ significantly from $0(p<0.1)$. The model performs very well: $94.4 \%$ of the null deviance is explained and adjusted $\mathrm{R}^{2}$ is very high as well $(0.957)$. We also verified the assumptions of the model. Although the model seems to struggle to a certain extent with the large differences in the amount of smoothing needed per semantic field, the results presented here are robust for models in which different numbers of basis functions are allowed for the calculation of the smooth term

\footnotetext{
${ }^{10}$ French loanwords also occur frequently in Standard Dutch. Additionally, at the time of the collection of the dialect questionnaires, they were more frequent in the colloquial variety of Dutch in Belgium than in the Netherlands (Geeraerts et al., 1999). However, if French variants that were also accepted in Standard Dutch at the time of the questionnaire collection, are excluded from the analysis, the geographical patterns in the data remain highly comparable in every semantic field. Although the overall proportion of French is smaller, we still find more French in the fields of clothing \& personal hygiene and society, school \& education, and the difference between Belgium and the Netherlands remains clearly visible in these fields as well.
} 
[insert Figure 4 about here]

Figure 4: Latin tokens per location per semantic field

Figures 4a-d present the visual output of the model for the amount of Latin per location. In these graphs, the colour scale ranges from the odds of encountering a Latin token equal to 0.01 (red hues) to 0.1 (yellow hues). The highest predicted value for the odds of encountering a Latin loanword is 0.09 , which indicates that these borrowings are clearly less frequent overall than lexical borrowings from French. The maps for the semantic fields 'personality \& feelings' and 'clothing \& personal hygiene' do not contain any colour or isoglosses. This indicates that the predicted odds of encountering a Latin token in a location in these fields is even smaller than 0.01: the maximum predicted value for clothing concepts is 0.004 (in Deurne, province of Antwerp) and 0.002 for personality-related terms (in Vaals, province of Limburg in the Netherlands). For concepts from the field of society, school \& education, Latin tokens occur in some locations, albeit very infrequently. Overall, Latin seems to be used the most for concepts of this field in the Netherlands, although the pattern seems to indicate that these tokens are geographically almost randomly distributed. Only a few locations in the north of the Belgian provinces show predicted odds between 0.01 and 0.06 .

The field of church \& religion shows, as expected, the largest amount of Latin tokens. As outlined above, many of the Latin names were introduced into Dutch as names for novel concepts. Whether or not a lexical item is borrowed out of necessity (i.e. to avoid a lexical gap) or not, is frequently mentioned as a semantic factor that increases the borrowability of a lexeme. As a result, this factor may serve as an explanation for the success of the Latin source language in this semantic field. In contrast with the maps for the French loanwords, we do not find that the geographical distribution of the Latin loanwords forms an expansional pattern, like the wave pattern that was discussed above. However, although we did not expect to find geographical patterns in the spread of these variants for religion-related concepts, the results from the GAM indicate that Latin is used more in the two provinces of Limburg than in the Brabantic dialect area. On the one hand, the picture, thus, may reflect the boundaries between the two dictionaries 
that are combined in the data. It may be the case that the Latin loanwords were more consistently tagged in the WLD than in the WBD, resulting in a seemingly larger number of Latin vis-à-vis other items in Limburg. However, as outlined above, we controlled for differences between the sources by labelling word forms that were marked in one dictionary as French, Latin or German, as non-native in the other dictionary as well (and vice versa). As a result, another interpretation seems more likely.

More specifically, this spatial distribution can also reflect cultural patterns: perhaps people in Limburg are more oriented towards the Roman Catholic church than the Brabantic dialect users and, as a result, are more familiar with the traditional Latin names. Perhaps the Limburgish dialect speakers find it more important to retain these traditional Latin names for the church concepts than the people from Brabant, who also rely on other variants. There is some evidence which suggests that this interpretation holds. First, Limburg in the Netherlands has a higher density of pilgrimage locations that were installed in the last 200 years (Margry \& Caspers, $2000: 11-12)$. Second, in Belgium, the percentage of catholic baptisms, weddings and funerals and of people who attend church on Sundays in 2009 is smaller in the central cities, which are mostly located in the Brabantic dialect region, than on the countryside, which includes Limburg (Havermans \& Hooge, 2011). Third, the cultural differences between the Brabantic and Limburgish dialect region are also corroborated by self-reported census data collected in the Netherlands between the 1849 and 2013 (Schmeets, 2014). Figure 5 shows the percentage of Catholics in the provinces of Limburg (in the Limburgish dialect area) and North Brabant (in the Brabantic dialect area) in the Netherlands (Schmeets, 2014: 6). The Figure shows that the percentage of Catholics has been decreasing more quickly in North-Brabant than in Limburg. Since the 1980s, the gap between North Brabant and Limburg has become particularly large. Crucially, most of the dialect data for the field of church \& religion in both dictionaries were only collected in the late 1980s.

\section{[insert Figure 5 about here]}

Figure 5: Percentage of (self-reported) Catholics in the provinces of North Brabant and Limburg in the Netherlands from 1849 until 2013 (Schmeets, 2014: 6) 


\subsection{German Loanwords}

For the German loanwords, we also used the same formula to determine the influence of semantic field and geography on the variation in the data, with an interaction between longitude and latitude by semantic field and a random effect for location (the numerical output of the GAMM is included in Appendix 1C). We verified the significance of these predictors and the assumptions of the regression model. Although the model diagnostics show that the model struggles somewhat with the general infrequency of German tokens in the dialect data, overall, it performs well. It explains $89.2 \%$ of the variation in the German versus non-German tokens (adjusted $\mathrm{R}^{2}=0.928$ ). In Figures 6a-d, the predictions of the GAMM are presented visually. As for a large number of locations the predicted odds of encountering a German loanword are equal to 0 , the lower bound of the maps is set to a very small number $(0.001)$. The upper bound is equal to the maximum of the predicted odds for German (0.207), to ensure comparability between the different semantic fields.

\section{[insert Figure 6 about here]}

Figure 6: German tokens per location per semantic field

Figure 6 shows that for German, border effects are again present in the data. More specifically, in the semantic field of society, school \& education, the GAMM clearly shows that there is a difference between Belgium and the Netherlands: while no German is predicted in Belgium, it occurs much more in the Netherlands, especially near the border with Germany. Interestingly, as section 4.1 showed, French tokens occur more frequently in this field in Belgium. As a result, the use of German and French may be distributed complementarily: while dialect speakers from the Netherlands use German tokens, Belgian dialect users rely on French. This is not surprising as the French culture held a stronger position for a longer period in Belgium than in the Netherlands. However, it should be noted that the odds of encountering a German token in the Netherlands are much lower than the odds of finding a French token 
in this field in Belgium, so the Netherlandic dialect speakers rely on other naming strategies for societyrelated concepts as well. In the other semantic fields, expansional patterns show up as well, although the difference between Belgium and the Netherlands is no longer visible. More specifically, the use of German tokens is geographically the most widespread in the semantic field of church \& religion. While, unsurprisingly, German tokens occur in the entire Brabantic and Limburgish dialect area, they are especially frequent closer to the border with Germany. In the semantic fields of personality \& feelings and clothing \& personal hygiene, the amount of German that is used also becomes smaller when dialect speakers live further away from the border with Germany.

Table 8: Locations with the highest proportion of German in three semantic fields

\section{[insert Table 8 about here]}

Interestingly, the border effect in three of these semantic fields (viz. society, school \& education, personality \& feelings and church \& religion) is not only related to geographical closeness to Germany, but it also stems from a small area in the south-east of Limburg in the Netherlands. In fact, the green lines on each of these maps, which can be interpreted like isoglosses, seem to demarcate a small area, where the use of German is exceptionally high, from the rest of Limburg in the Netherlands (also see the bubble plots in Figure 2). Table 8 shows the five locations with the highest proportion of German tokens per semantic field. ${ }^{11}$ Notably, locations belonging to three municipalities take up a high position in every semantic field: Kerkrade, Simpelveld and Vaals. Importantly, in these locations, east of the Benratherlinie (the machen/maken line), Ripuarian dialects are spoken (Van de Wijngaard, 2007; Van de Wijngaard \& Keulen, 2007). These dialects differ from the other Limburgish dialects due to the fact that they did undergo the second Germanic (High German) consonant shift.

\footnotetext{
${ }^{11}$ While we included both lexical items that were marked as German and lexemes that were marked as Ripuarian in the calculation of the ratio of German tokens per location, only one token in this area is marked as Ripuarian in the data (viz. Bohei 'fuss', which was recorded in Kerkrade). All the other tokens that are presented in Table 8 are marked as High-German in the dictionaries. Furthermore, 95 out of these 100 German word types occur in the online version of the German $\underline{\text { Duden }}$ dictionary (http://www.duden.de, Accessed on 17 July 2017).
} 
Traditionally and until the beginning of the $20^{\text {th }}$ century, the locations belonging to the Ripuarian dialect region in the Netherlands were oriented towards Aachen. As a result, it is not surprising that the use of German in these locations is high for the semantic fields 'society, school \& education' and 'church $\&$ religion', two fields that are prone to borrowing. However, Table 8 indicates that dialect speakers of this region also rely on loanwords related to the field of personality \& feelings, which contains concepts that are generally thought to be universal and, thus, not prone to borrowing. In fact, in these locations, the proportion of German tokens for this semantic field is higher than the proportion of German for other semantic fields (it reaches an observed value of 0.18 or more). Two interpretations for this finding can be envisaged. On the one hand, the differences between the semantic fields may reflect an older dialect situation. More specifically, if we assume that universal concepts, like those of the field of personality \& feelings are not prone to borrowing (in this case from Standard Dutch) and, thus, to language change at large, it may be the case that Ripuarian dialect speakers still use the old Ripuarian words, which happen to be part of Standard German as well, as they are not marked in the dictionary as typically Ripuarian lexemes. Recall that for the French loanwords, we found a similar pattern (more French for personalityrelated concepts near the border with Wallonia). This may serve as evidence for the fact that the use of foreign material for personality-concepts in contact situations actually reflects bilingualism of the speakers. On the other hand, the concepts from the field of personality \& feelings show a large amount of variation in general. Perhaps these concepts are prime candidates for geographical variability (in this case: the use of German loanwords in a relatively limited area) because they are highly expressive. Weinreich (1968: 58-59), for instance, argues that affect-laden concepts quickly lose their expressive meaning, which makes them prone to borrowing as language users need to be able to convey this expressive meaning. As a result, it may be the case that the dialect users rely on the German loanwords for this reason.

Tentative evidence for the second explanation comes from the fact that not every concept belonging to the field of personality \& feelings for which data is available in more than one of the Ripuarian dialect locations (viz. Kerkrade, Vaals and Simpelveld), is expressed with the same German word. More 
specifically, for 21 out of the 94 concepts for which a German type is used in the Ripuarian dialect area, more than one German type occurs (see Appendix 2, which contains the data for the "German"12 concepts that occur in at least two locations in the Ripuarian dialect area in the semantic field of personality \& feelings). Furthermore, the mean proportion of German tokens per concept from this field in these locations is only 0.541 , which means that only half of the "German" concepts are expressed with a German token in more than one Ripuarian dialect location in the Netherlands. A BRAT (SNOTNEUS), for instance, is named a vorwitzig (German) in Vaals, while it is called a muilenjan, snotnaas, kute-naas or kute-nelis in Kerkrade. However, for five (not very expressive) concepts out of the 94 (viz. DECENT (gründlich), TO FORCE (zwingen), SIMPLE (einfach), SOBER (einfach) and CHASTE (anständig)), one German word type does seem conventionalized to some extent, as it is used in more than one Ripuarian town.

In conclusion, most of the German words for personality \& feelings concepts, are not highly entrenched and conventionalized, which makes it less likely that they stem from an older period. For only five concepts, one German word type occurs in more than one Ripuarian location. As a result, for most of the German tokens in this semantic field, the second explanation outlined above seems like the most likely one: personality \& feelings concepts can be highly expressive, which results in dialect speakers relying on loanwords to convey extra (social) meaning. However, for the five concepts that do show a high amount of conventionalization, the German type may reflect an older language situation. Additional research is necessary to corroborate these explanations further.

\section{DISCUSSION AND CONCLUSION}

The main aim of this paper was to analyse the distribution of loanwords from different source languages in the Brabantic and Limburgish dialects of Dutch. We used Generalized Additive Modelling to ensure that predictors with a non-linear relationship to the response variable could be included in the

\footnotetext{
${ }^{12}$ We use the term "German" concept informally to indicate that the concept has at least one German token.
} 
analysis as well. This methodology allowed us to show that the amount of loanwords is highly dependent on the interaction between semantics and geography. On the one hand, we find clear differences between the source languages. Lexical borrowings from French occur the most, while German is infrequent overall. This reflects the large influence of French culture throughout history. On the other hand, clear and systematic patterns of variation in the use of loanwords from a single source language are significant as well. More specifically, these patterns reveal different types of spatial diffusion of lexical variants through language contact. As they often differ between semantic fields, they confirm that historical and sociocultural differences characterize the use of loanwords in the Brabantic and Limburgish dialect area.

As predicted in Table 4, French was found to be especially frequent in the field of clothing terminology and, to a lesser extent, also in the field of society, school \& education. Interestingly, the geographical pattern is not the same in the two semantic fields (cf. Figure 3): the map for clothing \& personal hygiene clearly shows that French is much more frequent for these concepts in Belgium than in the Netherlands. In the field of society, school \& education, French additionally also occurs relatively frequently in the province of Limburg in the Netherlands.

Latin loanwords are, as expected, especially dominant in the field of church \& religion. This is not surprising as many of these words were introduced as necessary loanwords: as novel concepts enter the language, the original (non-native) name for the concept is borrowed as well. However, in contrast with what we predicted in Table 4, we did find geographical differences in the spread of the Latin variants. These differences were explained as the result of a cultural difference between the Limburgish and Brabantic dialect area. More specifically, it may be the case that the dialect speakers from the Limburgish dialect area are more oriented towards the Roman Catholic tradition than people from the Brabantic region, which is reflected in their more systematic use of the Latin variant.

German loanwords occur throughout the dialect areas in the semantic field of church \& religion. Additionally, two interesting geographical patterns show up in this and other semantic fields as well. First, for concepts from the field of society, school \& education, German is only used in the Netherlands. 
Interestingly, we found the opposite pattern for the loanwords of French, which are more frequent in Belgium. This may indicate that French and German are complementarily distributed in this semantic field, which can be related to the fact that French culture held a stronger position in Belgium than in the Netherlands. Second, in three out of the four GAMM maps for German, the Ripuarian dialect area is clearly demarcated. In this region, German tokens are always more frequent, even in the semantic field of personality \& feelings. Thus, the expansional patterns that we predicted in Table 4 show up in more semantic fields than expected. A small-scale analysis of the systematicity in the use of German tokens in this region for personality-related concepts, revealed that the use of German is not highly systematic. Only for five concepts, a single German word type is used in every Ripuarian location. As most of the German words in the Ripuarian region are, therefore, not highly conventionalized and as many of these personality-related concepts are relatively expressive, it is possible that people living close to the German border use these words to convey extra social meaning.

Geographically, the GAM(M)s, thus, revealed different types of spatial diffusion. First, for French and German loanwords, expansional patterns show up. The closer to the Brussels area and to the GermanicRomance border a dialect speaker lives, the more French loanwords (s)he uses. The closer to the Ripuarian dialect area and to the state border with Germany, the more German occurs. In other dialectometric research, expansional patterns have been observed as well, that are related to geographical closeness with a prestigious geographical region. Wieling, Nerbonne \& Baayen (2011), for instance, show that the geographically farther away from the economic and politically dominant region a dialect is located, the larger the pronunciation difference with Standard Dutch. A second spatial pattern that was apparent concerns the effect of the state border, again for French and German. In the northern part of Belgium, much more French is used for clothing terms and for society-related terminology and in the former semantic field, the isoglosses even seem to follow the border between Belgium and the Netherlands (Figure 3d). German also occurs much more frequently in the Netherlands than in Belgium for society-related concepts. These within-state patterns have probably also come about through more 
intensive contact with speakers of the particular source language. Crucially, the spatial patterns for loanwords from Latin are of a completely different nature. We do not find any type of expansional or within-state spatial distribution. If geographical variation is present, like in the semantic field of church \& religion, it can only be related to cultural differences between the dialect areas, not to a higher degree of contact with the source language.

On the basis of these findings, we can distinguish general implications for the borrowability of lexical material. First, in every semantic field and for every source language, systematic patterns show up that correlate to a large extent with historical evolution and the socio-cultural environment of a dialect user. As has been noted frequently in previous research (e.g. Backus, 2014), loanword usage reflects cultural contact. This is apparent from the different types of geographical patterns that show up. Most of these patterns can only be explained by taking into account the socio-cultural history of the dialect speakers. The influence of an exoglossic variety shows up in differences concerning the use of French between the two countries where Dutch is spoken, and between the Limburgish and Brabantic language area in the use of Latin. Additionally, lexical items are also borrowed directly into the base dialects, often due to a small geographical distance to the speakers of the source language. More specifically, the border effects that were distinguished for German in the Ripuarian dialect area and for French at the Germanic-Romance language border and in the Brussels region, indicate that the distribution of loanwords in a dialect area is not only dependent on culture, but also reflects geographical closeness. In sum, the full system of loanword usage only becomes clear when the complex interaction between culture and geography is taken into account. This is in line with recent work on lexical borrowing which advocates a multifactorial approach to lexical borrowing (Zenner \& Kristiansen, 2014: 8-10). Another implication for the borrowability of linguistic data is apparent from the comparison of the distribution of lexical items in the field of personality \& feelings with the other semantic fields. We provide further evidence for the fact that more universal concepts are less prone to borrowing. These concepts are hardly ever expressed with nonnative lexical items, except in regions that have a higher degree of bilingualism, like the Ripuarian dialect 
area. Finally, some scholars have argued that loanwords are copied easier from a less closely related variety (e.g. Weinreich, 1968: 1-2), while lexical borrowings from a genetically close language are phonologically adapted to the language system more easily (Van der Sijs, 2005: 257). We can only answer this question tentatively, because both French and Latin culture were more important for people from Belgium and the Netherlands than German culture. The data indicate that the proportion of loanwords from Latin and, especially, from French is much higher than the loanwords from German. As a result, the data corroborate the observation that the amount of lexical items that are borrowed from a closely related language in their original form is smaller.

However, a shortcoming of this study is that we did not take into account characteristics of the concepts themselves. Previous research has shown that properties like the sensitivity to affect of a particular meaning may influence the amount of variation that is found (Franco et al., In press; also see Weinreich, 1968: 58-59). Additionally, it may be necessary to take into account the period when a particular concept or artefact was introduced into the Dutch culture and language. For Latin, for instance, Van der Sijs (2005) provides a list of loanwords that were already borrowed in the Romance era, like defensie 'military defense', and munt 'coin'. These older lexical items, which have been present in the dialects for a longer time, are probably more conventionalized and, thus, probably, more widespread. As a result, it is possible that the concepts for which these types of lexemes are used, show less lexical variation in general. Furthermore, micro-level geographical patterns in the distribution of separate variants probably differ as a result of cultural or political changes as well. Consequently, taking into account a factor like the age of the lexeme or concept, or comparing these relatively recent dialect data to material from an older time period, would elucidate the importance of diachronic evolution further. Further, we only focused on the use of borrowed material, but follow-up research can be envisaged that investigates whether other naming strategies also differ as a function of historical or socio-cultural factors. Taking into account this type of variation can offer more insight into the question of how a particular lexical item becomes entrenched: if several options are available, why are some concepts expressed with loanwords in one 
location, while language users from a different place rely on names that are, for instance, based on a property of the referent itself, or on hyperonymic variants? Such research could, for instance, provide additional explanations for the use of German tokens in the Ripuarian dialect area. Finally, in this study, we did not pay attention to the context in which a particular lexical item occurs. More specifically, in the analyses, we relied on data collected by means of large-scale dialect questionnaires, but it may be the case that discursive features, like register or speech partner, also influence the variants that are used. Consequently, the geographical patterns that are found should be examined in differently stratified data as well.

However, overall, in this paper we were able to show that the use of loanwords varies as a function of geography and semantic field. By taking an onomasiological perspective to variation in loanword usage and by using sophisticated quantitative techniques and a semantically diverse dataset, we demonstrated that the patterns that occur, almost exclusively reflect changes in socio-cultural history.

\section{References}

Auer, Peter. 2005. Europe's sociolinguistic unity, or: A typology of European dialect/standard constellations. In Nicole Delbecque, Johan Van der Auwera \& Dirk Geeraerts (eds.), Perspectives on Variation. Sociolinguistic, Historical, Comparative, 7-42. Berlin \& Boston: De Gruyter Mouton.

Backus, Ad. 2014. A usage-based approach to borrowability. In Eline Zenner \& Gitte Kristiansen (eds.), New perspectives on lexical borrowing: Onomasiological, methodological and phraseological innovations (Language contact and bilingualism 7), 19-40. Boston: De Gruyter Mouton.

Cornelissen, Georg. 2007. Uit de woordenschat van het Kerkraads: Duitse woorden [The vocabulary of the Kerkraad dialect: German words]. In Ronny Keulen \& Herman Crompvoets (eds.), Riek van klank: Inleiding in de Limburgse dialecten [Wealth of sound: introduction to the Limburgish dialects] (Veldeke taalstudies 2), 60-65. Sittard: Veldeke Limburg.

Crawley, Michael J. 2007. The R book. Chichester: Wiley.

Daems, Jocelyne, Kris Heylen \& Dirk Geeraerts. 2015. Wat dragen we vandaag: Een hemd met blazer of een shirt met jasje? [What to wear today: een hemd met blazer ('a dress shirt with suit jacket') or een 
shirt met jasje ('a dress shirt with suit jacket')? Convergence and divergence in Dutch clothing terminology]. Taal en Tongval 67(2). 307-342.

De Vriend, Folkert, Charlotte Giesbers, Roeland Van Hout \& Louis Ten Bosch. 2008. The Dutch-German Border: Relating Linguistic, Geographic and Social Distances. International Journal of Humanities and Arts Computing 2(1-2). 119-134.

De Vriendt, Sera. 2004. Brussels (Taal in stad en land 2). Tielt: Lannoo.

Franco, Karlien. 2017. Concept features and lexical diversity. A dialectological case study on the relationship between meaning and variation. $\mathrm{PhD}$ dissertation. Leuven \& Nijmegen: University of Leuven \& Radboud University.

Franco, Karlien, Dirk Geeraerts, Dirk Speelman \& Roeland van Hout. In press. Concept characteristics and variation in lexical diversity in two Dutch dialect areas. To appear in Cognitive Linguistics.

Geeraerts, Dirk, Stefan Grondelaers \& Dirk Speelman. 1999. Convergentie en divergentie in de Nederlandse woordenschat: een onderzoek naar kleding- en voetbaltermen [Convergence and divergence in the vocabulary of Dutch: a study into clothing and football terminology]. Amsterdam: Meertens Instituut.

Geeraerts, Dirk, Gitte Kristiansen \& Yves Peirsman. 2010. Advances in Cognitive Sociolinguistics (Cognitive linguistics research 45). Berlin: De Gruyter Mouton.

Giesbers, Charlotte. 2008. Dialecten op de grens van twee talen: een dialectologisch en sociolinguïstisch onderzoek in het Kleverlands dialectgebied [Dialects at the border of two languages: a dialectological and sociolinguistic study in the Kleverland dialect area]. Nijmegen: Radboud University PhD dissertation.

Haspelmath, Martin \& Uri Tadmor. 2009. World Loanword Database. Leipzig: Max Planck Institute for Evolutionary Anthropology. http://wold.clld.org (accessed 19 July 2017).

Havermans, Nele \& Marc Hooge. 2011. Kerkpraktijk in België: Resultaten van de zondagstelling in oktober 2009. Rapport ten behoeve van de Belgische Bischoppenconferentie [Church practices in Belgium: Results of the Sunday count in October 2009. Report for conference of Belgian bishops]. Leuven: KU Leuven, Centrum voor Politicologie.

Hinskens, Frans, Jeffrey L. Kallen \& Johan Taeldeman. 2000. Merging and drifting apart. Convergence and divergence of dialects across political borders. International Journal of the Sociology of Language 145. 1-28.

Hock, Hans H. \& Brian D. Joseph. 1996. Language history, language change, and language relationship: An introduction to historical and comparative linguistics (Trends in linguistics. Studies and monographs 93). Berlin: De Gruyter. 
Janssens, Guy \& Ann Marynissen. 2008. Het Nederlands vroeger en nu [Dutch past and present]. Leuven: Acco.

Kristiansen, Gitte \& René Dirven. 2008. Cognitive Sociolinguistics (Cognitive Linguistics Research 39). Berlin \& New York: De Gruyter Mouton.

Kruijsen, Joep. 1990. Woordgeografie van ontleningen in een taalcontactsituatie [Word geography of loanwords in a language contact situation]. Taal en Tongval 52. 4-45.

Kruijsen, Joep. 1995. Geografische patronen in taalcontact. Romaans leengoed in de Limburgse dialecten van Haspengouw. [Geographical patterns in language contact. Roman borrowings in the Limburgish dialects in the Hesbaye.] PhD dissertation. Nijmegen: Radboud University.

Margry, Peter J. \& Charles Caspers. 2000. Bedevaartplaatsen in Nederland: Limburg [Places of pilgrimage in the Netherlands: Limburg]. Amsterdam: Meertens Instituut.

McMahon, April. 1994. Understanding language change. Cambridge: Cambridge University press.

Onysko, Alexander \& Esme Winter-Froemel. 2011. Necessary loans - luxury loans? Exploring the pragmatic dimension of borrowing. Journal of Pragmatics 436. 1550-1567.

OpenStreetMap contributors. s.d. OpenStreetMap. https://www.openstreetmap.org (accessed 20 December 2018).

Paul, Hermann. 1981. Principles of the History of Language. Translated from the Second Edition of the Original by H.A. Strong, M.A., L.L.D. London: Longmans, Green and co.

Poplack, Shana, David Sankoff \& Cristopher Miller. 1988. The social correlates and linguistic processes of lexical borrowing and assimilation. Linguistics 26. 47-104.

$\mathrm{R}$ Core Team (2018). R: A language and environment for statistical computing. Vienna: R Foundation for Statistical Computing. https://www.R-project.org/.

Schmeets, Hans. 2014. De religieuze kaart van Nederland, 2010-2013 [The religious map of the Netherlands, 2010-2013]. s.d.: Centraal Bureau voor de Statistiek.

Swadesh, Morris. 1955. Towards greater accuracy in lexicostatistic dating. International Journal of American Linguistics 21(2), 121-137.

Tadmor, Uri. 2009. Loanwords in the world's languages: Findings and results. In Martin Haspelmath \& Uri Tadmor. Loanwords in the World's Languages, 55-75. Berlin \& Boston: De Gruyter Mouton.

Tadmor, Uri, Martin Haspelmath \& Bradley Taylor. 2010. Borrowability and the notion of basic vocabulary. Diachronica 272, 226-246..

Thomason, Sarah G. \& Terrence Kaufman. 1991. Language contact, creolization, and genetic linguistics. Berkeley: University of California press.

Van Bree, Cor \& Marijke Van der Wal. 2008. Geschiedenis van het Nederlands [History of Dutch]. Utrecht: Spectrum. 
Van de Wijngaard, Ton. 2007. De Ripuarische dialecten [The Ripuarian dialects]. In Ronny Keulen \& Herman Crompvoets (eds.), Riek van klank: Inleiding in de Limburgse dialecten [Wealth of sound: introduction to the Limburgish dialects] (Veldeke taalstudies 2), 45-59. Sittard: Veldeke Limburg. Van de Wijngaard, Ton \& Ronny Keulen. 2007. De indeling van de Limburgse dialecten. ]. In Ronny Keulen \& Herman Crompvoets (eds.), Riek van klank: Inleiding in de Limburgse dialecten [Wealth of sound: introduction to the Limburgish dialects] (Veldeke taalstudies 2), 15-23. Sittard: Veldeke Limburg.

Van der Sijs, Nicoline. 2005. Groot leenwoordenboek. Utrecht: Van Dale Lexicografie.

Van der Sijs, Nicoline \& Jaap Engelsman. 2000. Nota bene: De invloed van het Latijn en Grieks op het Nederlands [Nota bene: The influence of Latin and Greek on Dutch]. 's-Gravenhage: SDU.

Van Hout, Roeland, Joep Kruijsen \& Marinel Gerritsen. 2014. Exosmosis along the Romance-Germanic language border in Belgium: The diffusion of French borrowings in the Dutch dialects of Haspengouw. In Raquel Casesnoves-Ferrer, Montserrat Forcadell Guinjoan \& Núria Gavaldà Ferré (eds.), Ens queda la paraula: Estudis de lingüistica aplicada en honor a M. Teresa Turell, 197-220. Barcelona: Institut Universitari de Lingüística Aplicada.

Van Keymeulen, Jacques. 2008. Latijnse leenwoorden in het Nederlands en de Nederlandse dialecten [Latin loanwords in Dutch and in the Dutch dialects]. Van Mensen en Dingen. Tijdschrift voor Volkscultuur in Vlaanderen 6. 69-85.

Van Rij, Jacoline. 2015. Overview GAMM analysis of time-series data. http://www.sfs.unituebingen.de/ jvanrij/Tutorial/GAMM.html (accessed 4 July 2017).

WBD $=$ Woordenboek van de Brabantse Dialecten [Dictionary of the Brabantic dialects]. 1967-2005. Assen: Van Gorcum \& Amsterdam: Gopher.

Weijnen, Antonius A. 1967. Leenwoorden uit de Latinitas stratigrafisch beschouwd. Verslagen en mededelingen van de Koninklijke Academie voor Nederlandse taal- en letterkunde 5. 365-480.

Weinreich, Uriel. 1968. Languages in contact: Findings and problems. The Hague: De Gruyter Mouton.

Wieling, Martijn. 2017. Statistics course on generalized additive modelling. http://www.let.rug.nl/ wieling/statscourse/ (accessed 4 July 2017).

Wieling, Martijn. 2018. Analyzing dynamic phonetic data using generalized additive mixed modeling: A tutorial focusing on articulatory differences between L1 and L2 speakers of English. Journal of Phonetics 70. 86-116.

Wieling Martijn John Nerbonne and R. Harald Baayen. 2011. Quantitative Social Dialectology: Explaining Linguistic Variation Geographically and Socially. PLOS ONE 6(9). e23613.

Willemyns, Roland. 2013. Dutch: Biography of a language. New York: Oxford University Press. 
Winford, Donald. 2010. Contact and borrowing. In Raymond Hickey (ed.), The Handbook of Language Contact, 170-187. Chichester: Wiley-Blackwell.

$\mathrm{WLD}=$ Woordenboek van de Limburgse Dialecten [Dictionary of the Limburgish dialects]. 1983-2008. Assen: Van Gorcum \& Amsterdam: Gopher.

Wood, Simon. 2006. Generalized additive models: An introduction with $R$ (Texts in statistical science). Boca Raton: Chapman and Hall/CRC.

Wood, Simon. 2017. Mixed GAM Computation Vehicle with GCV/AIC/REML Smoothness Estimation. https://cran.r-project.org/web/packages/mgcv/mgcv.pdf (accessed 15 March 2017).

Zenner, Eline \& Gitte Kristiansen. 2014. Introduction: Onomasiological, methodological and phraseological perspectives on lexical borrowing. In Eline Zenner \& Gitte Kristiansen (eds.), New perspectives on lexical borrowing: Onomasiological, methodological and phraseological innovations (Language contact and bilingualism 7), 1-17. Boston: De Gruyter Mouton.

Zenner, Eline, Dirk Speelman \& Dirk Geeraerts. 2012. Cognitive Sociolinguistics meets loanword research: Measuring variation in the success of anglicisms in Dutch. Cognitive Linguistics 23(4). 749792.

Zuur, Alain F., Elena N. Ieno, Neil J. Walker, Anatoly A. Saveliev \& Graham M. Smith. 2009. Mixed effects models and extensions in ecology with $R$ (Statistics for biology and health). New York: Springer. 


\section{Tables}

Table 1: Borrowing per semantic field in the Loanword Typology Project (Tadmor, 2009: 64)

\begin{tabular}{|l|r|}
\hline semantic field & loanwords as \% of total \\
\hline religion and belief & $41.2 \%$ \\
\hline clothing and grooming & $38.6 \%$ \\
\hline the house & $37.2 \%$ \\
\hline law & $34.3 \%$ \\
\hline social and political relations & $31.0 \%$ \\
\hline agriculture and vegetation & $30.0 \%$ \\
\hline food and drink & $29.3 \%$ \\
\hline warfare and hunting & $27.9 \%$ \\
\hline possession & $27.1 \%$ \\
\hline animals & $25.5 \%$ \\
\hline cognition & $14.0 \%$ \\
\hline basic actions and technology & $24.2 \%$ \\
\hline time & $23.8 \%$ \\
\hline speech and language & $19.9 \%$ \\
\hline quantity & $23.2 \%$ \\
\hline emotions and values & $17.3 \%$ \\
\hline the physical world & \\
\hline motion & \\
\hline kinship & \\
\hline the body & \\
\hline spatial relations & \\
\hline sense perception & \\
\hline & \\
\hline
\end{tabular}


Table 2: Subdomains of the field of society, school \& education in the WLD

\begin{tabular}{|l|l|}
\hline subdomain & examples \\
\hline man and society & e.g. trade, money, property, labour, language, communication \\
\hline societal organisation & $\begin{array}{l}\text { e.g. societal institutions, taxes, elections, police, law and crime, defence } \\
\text { and war }\end{array}$ \\
\hline transportation & by road, by railway, by air, over water \\
\hline education & e.g. people in school, the school building \\
\hline
\end{tabular}


Table 3: Subdomains of the field of personality \& feelings in the WLD

\begin{tabular}{|l|l|}
\hline subdomain & examples \\
\hline intellectual capacity and memory & e.g. thinking, knowing, smart, dumb, to judge/to consider \\
\hline personality & $\begin{array}{l}\text { e.g. (un)reliable, (in)sincere, diligent-lazy, brave-frightened, } \\
\text { conceited(ness) }\end{array}$ \\
\hline feelings & e.g. fun, laughter, anger, sadness, disappointment \\
\hline behaviour & $\begin{array}{l}\text { e.g. to behave, dominance, to (dis)obey, success-failure, } \\
\text { (in)decency }\end{array}$ \\
\hline
\end{tabular}


Table 4: Overview of hypotheses in relation to the semantic fields

\begin{tabular}{|c|c|c|c|c|}
\hline & $\begin{array}{c}\text { society, } \\
\text { school \& education }\end{array}$ & $\begin{array}{c}\text { clothing \& } \\
\text { personal hygiene }\end{array}$ & church \& religion & personality \& feelings \\
\hline $\begin{array}{l}\text { expected } \\
\text { source } \\
\text { language(s) }\end{array}$ & $\begin{array}{l}\text { - French } \\
\text { - German }\end{array}$ & French & $\begin{array}{l}\text { - Latin } \\
\text { - German }\end{array}$ & no borrowing \\
\hline $\begin{array}{l}\text { expected } \\
\text { geographical } \\
\text { patterns }\end{array}$ & $\begin{array}{l}\text { French: } \\
\text { - Belgium vs. } \\
\text { Netherlands } \\
\text { - expansional pattern } \\
\text { near Germanic-Romance } \\
\text { border and Brussels area } \\
\text { German: } \\
\text { expansional pattern near } \\
\text { border with Germany }\end{array}$ & $\begin{array}{l}\text { - Belgium vs. } \\
\text { Netherlands } \\
\text { - expansional pattern } \\
\text { near Germanic-Romance } \\
\text { border and Brussels area }\end{array}$ & no geographical variation & no geographical variation \\
\hline
\end{tabular}


Table 5: Example of the relevant columns from the semantic field of clothing \& personal hygiene in the WBD

\begin{tabular}{|l|l|l|l|}
\hline concept & $\begin{array}{l}\text { lexical item } \\
\text { (dutchified) }\end{array}$ & source & location \\
\hline armband 'bracelet' & bracelet (fr.) & N 86 (1981) & Aarschot \\
\hline armband 'bracelet' & bracelet (fr.) & N 86 (1981) & Aarschot \\
\hline armband 'bracelet' & armband & N 86(1981) & Aarschot \\
\hline armband 'bracelet' & armband & N 86(1981) & Halsteren \\
\hline armband 'bracelet' & bracelet (fr.) & N 86(1981) & Landen \\
\hline$\ldots$ & $\ldots$ & $\ldots$ & $\ldots$ \\
\hline borstrok 'undervest' & borstrok & N 02 (1960) & Attenhoven \\
\hline borstrok 'undervest' & slaaplijf & N 02 (1960) & Landen \\
\hline borstrok 'undervest' & borstrok & N 02 (1960) & Steenbergen \\
\hline borstrok 'undervest' & hemdrok & N 25 (1964) & Steenbergen \\
\hline borstrok 'undervest' & borstrok & N 25(1964) & N 25(1964) \\
\hline borstrok 'undervest' & hemdrok & & \\
\hline
\end{tabular}


Table 6: Examples of loanwords per source language and semantic field ${ }^{13}$

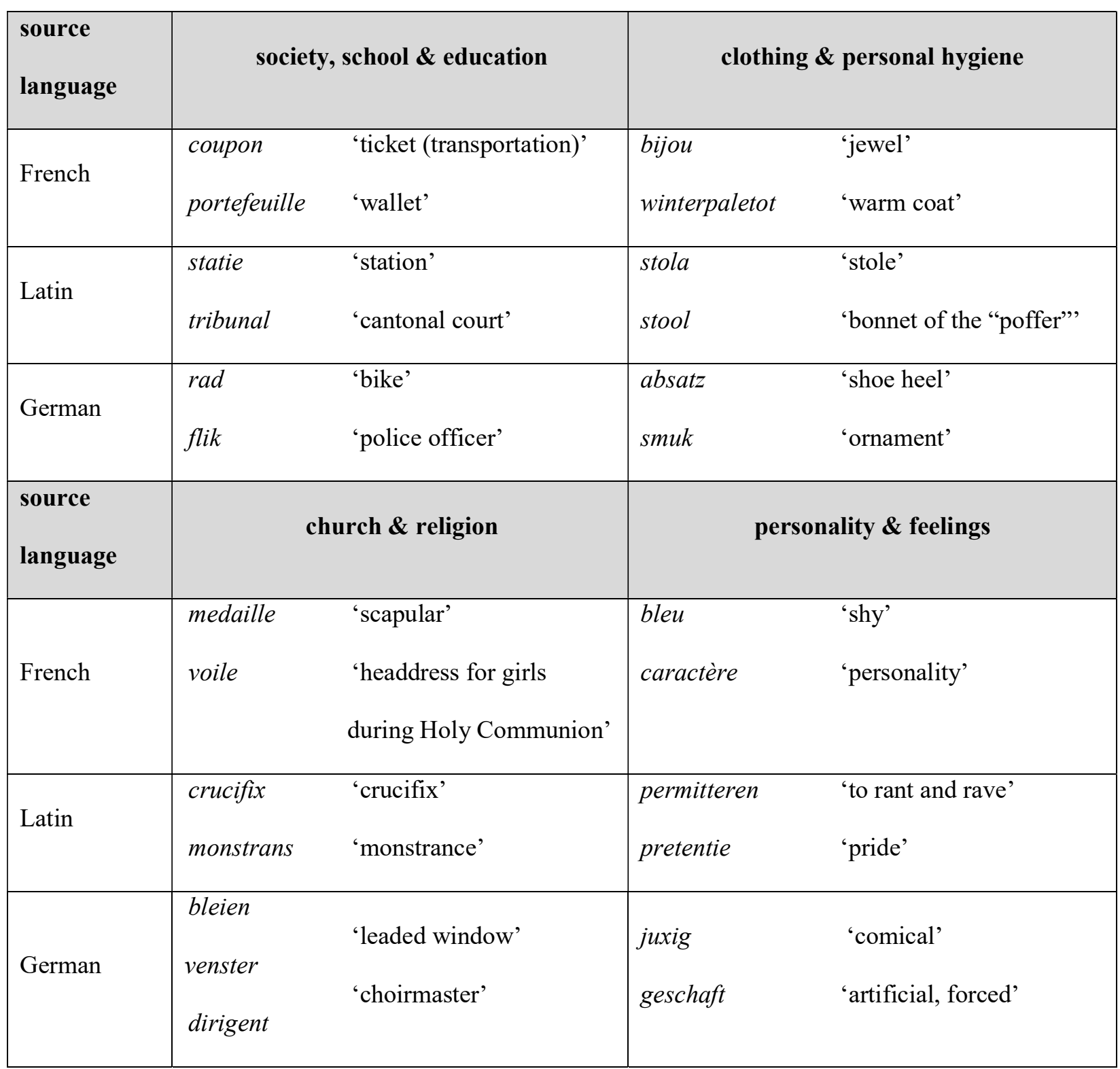

\footnotetext{
${ }^{13}$ Readers should only be able to sort this table per semantic field or source language, to avoid that meaning will be lost.
} 
Table 7: Absolute and relative number of French, Latin and German tokens per dictionary

\begin{tabular}{|l|r|r|}
\hline & \multicolumn{1}{|c|}{ WBD } & \multicolumn{1}{|c|}{ WLD } \\
\hline French & $16443(0.051)$ & $13015(0.059)$ \\
\hline not French & $305848(0.949)$ & $208353(0.941)$ \\
\hline Latin & $4361(0.014)$ & $5810(0.026)$ \\
\hline not Latin & $317930(0.986)$ & $215558(0.974)$ \\
\hline German & $318(0.001)$ & $2317(0.010)$ \\
\hline not German & $321973(0.999)$ & $219051(0.990)$ \\
\hline
\end{tabular}


Table 8: Locations with the highest proportion of German in three semantic fields

\begin{tabular}{|c|c|c|c|c|}
\hline $\begin{array}{l}\text { semantic } \\
\text { field }\end{array}$ & location (municipality) & $\begin{array}{c}\text { number of } \\
\text { German tokens }\end{array}$ & $\begin{array}{l}\text { number of non- } \\
\text { German tokens }\end{array}$ & $\begin{array}{c}\text { proportion of } \\
\text { German tokens }\end{array}$ \\
\hline \multirow{5}{*}{$\begin{array}{l}\text { society, } \\
\text { school \& } \\
\text { education }\end{array}$} & Amstenrade (Schinnen) & 4 & 78 & 0.049 \\
\hline & Nieuwenhagen (Landgraaf) & 34 & 595 & 0.054 \\
\hline & Mechelen (Gulpen-Wittem) & 16 & 253 & 0.059 \\
\hline & Kerkrade (Kerkrade) & 56 & 380 & 0.128 \\
\hline & Vaals (Vaals) & 16 & 105 & 0.132 \\
\hline \multirow{5}{*}{$\begin{array}{l}\text { personality \& } \\
\text { feelings }\end{array}$} & Eys (Gulpen-Wittem) & 93 & 827 & 0.101 \\
\hline & Nieuwenhagen (Landgraaf) & 71 & 617 & 0.103 \\
\hline & Kerkrade (Kerkrade) & 68 & 308 & 0.181 \\
\hline & Vaals (Vaals) & 68 & 244 & 0.218 \\
\hline & Simpelveld (Simpelveld) & 21 & 74 & 0.221 \\
\hline \multirow{5}{*}{$\begin{array}{l}\text { church \& } \\
\text { religion }\end{array}$} & Waubach (Landgraaf) & 28 & 1005 & 0.027 \\
\hline & Chèvremont (Kerkrade) & 4 & 91 & 0.042 \\
\hline & Bocholtz (Simpelveld) & 22 & 384 & 0.054 \\
\hline & Montzen (Montzen) & 40 & 580 & 0.065 \\
\hline & Kerkrade (Kerkrade) & 31 & 415 & 0.070 \\
\hline
\end{tabular}




\section{Figures}

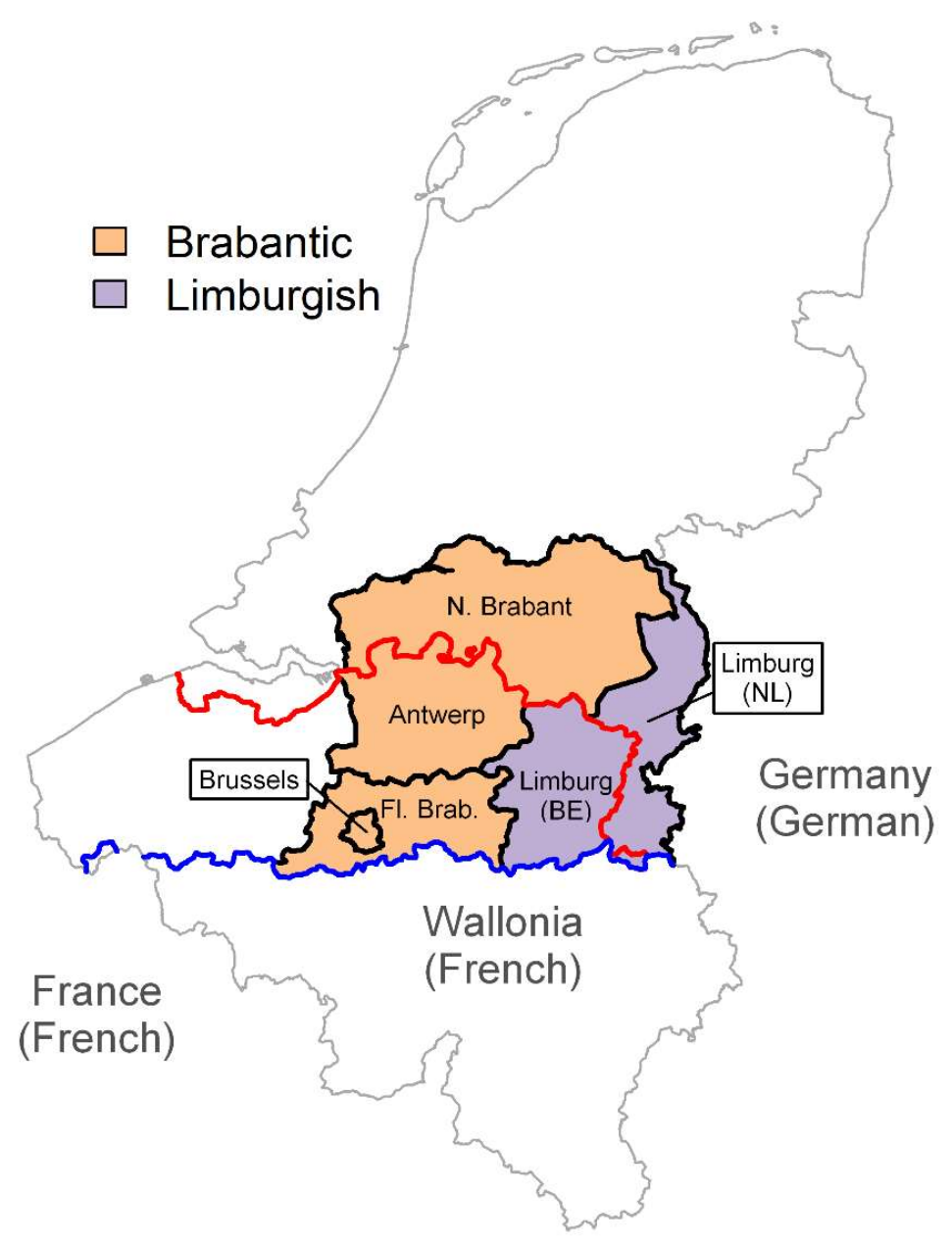

Figure 1: The Brabantic and Limburgish dialect areas 


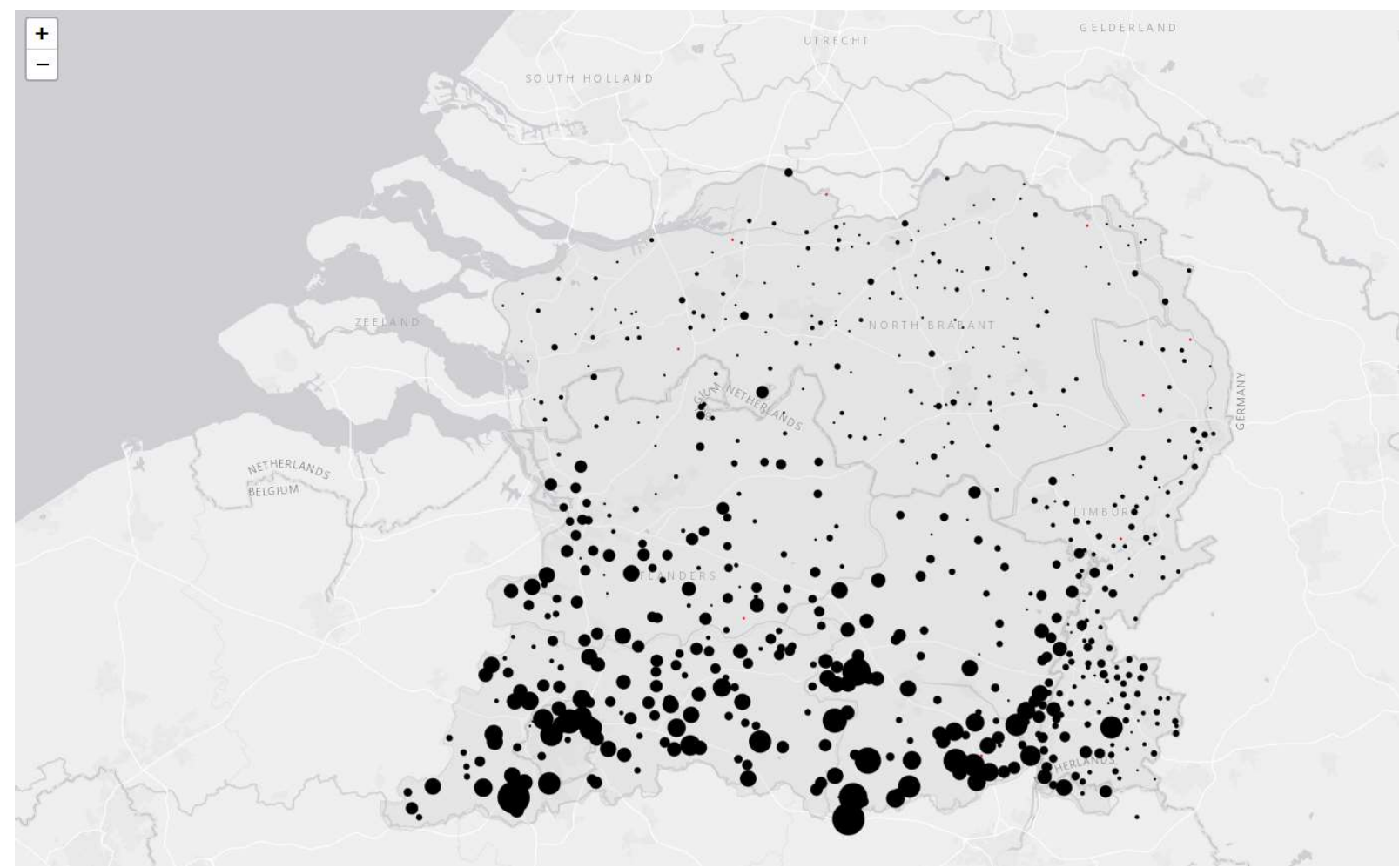

Figure 2a: Proportion of French tokens per location 


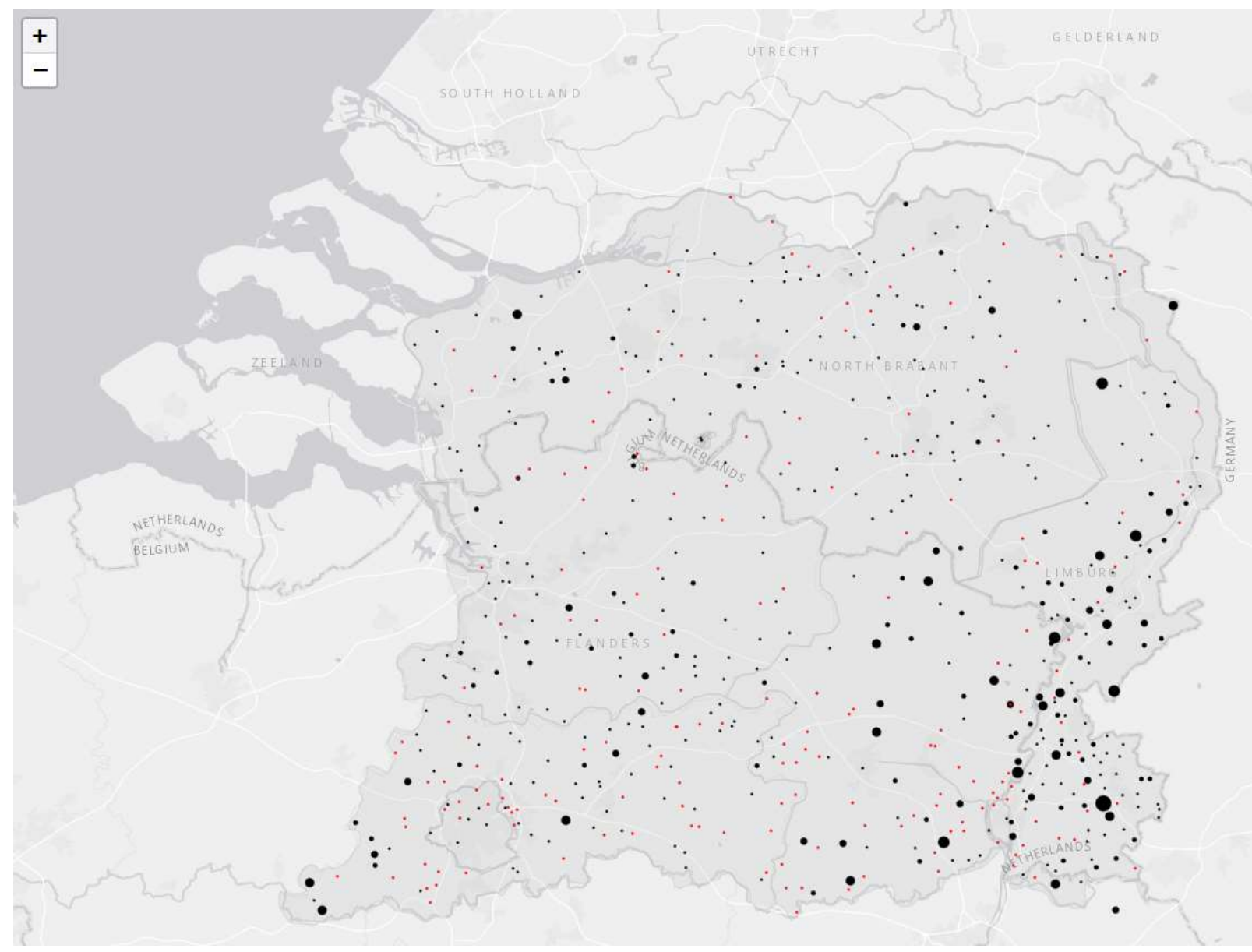

Figure 2b: Proportion of Latin tokens per location 


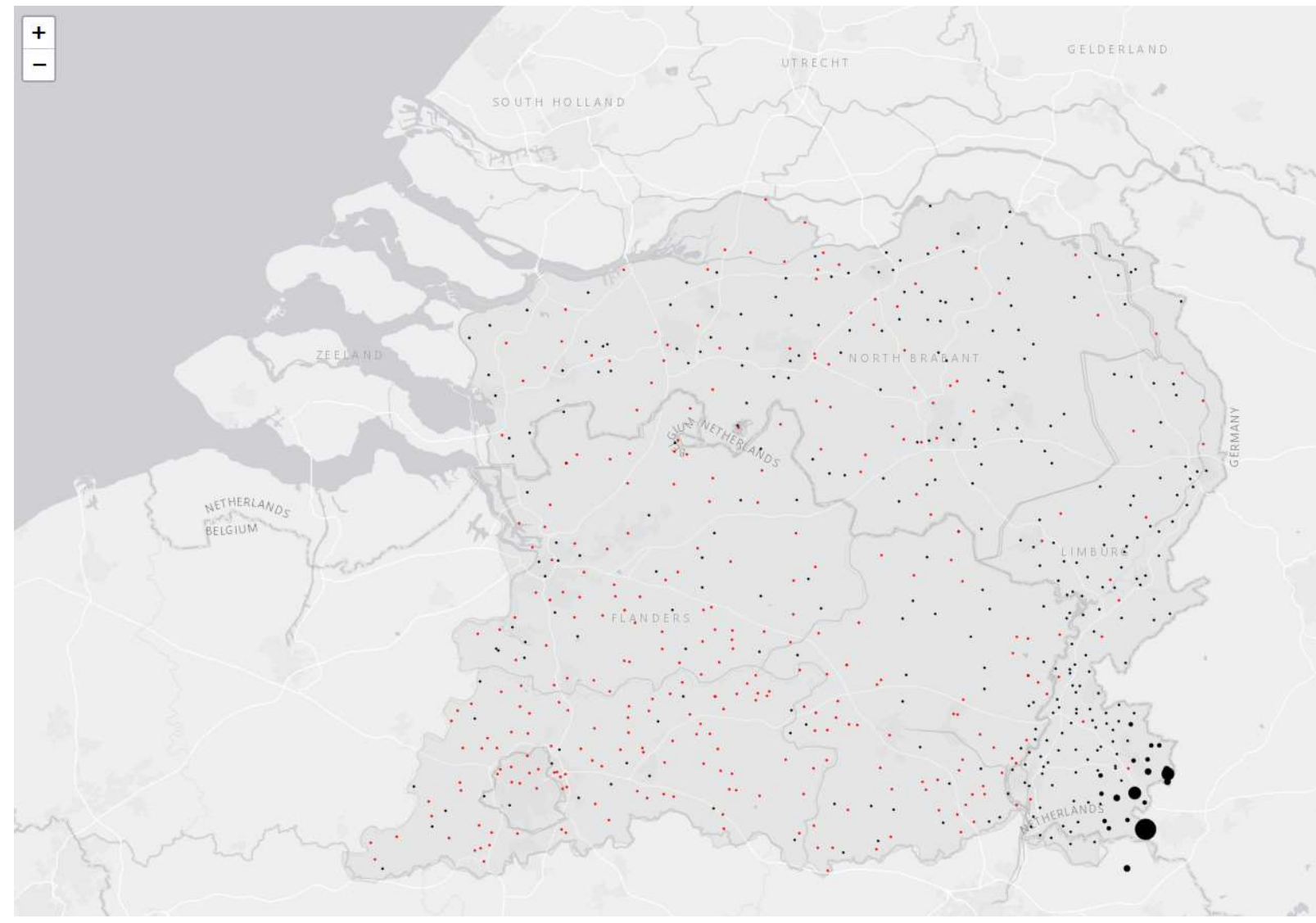

Figure 2c: Proportion of German tokens per location. 


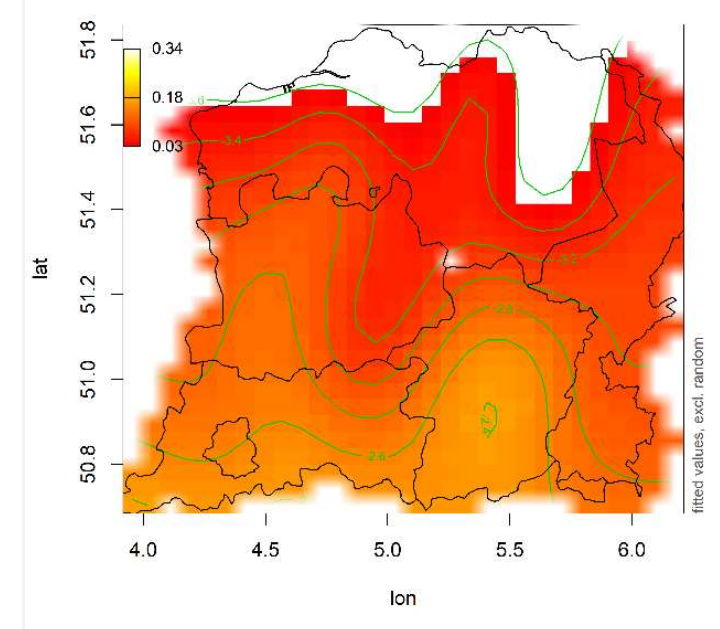

Figure 3a: French tokens per location (society, school \& education)

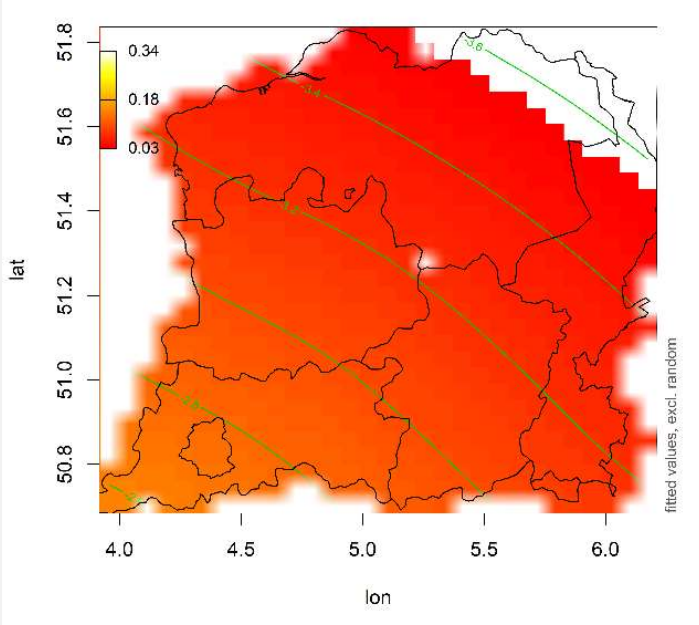

Figure 3c: French tokens per location (church \& religion)

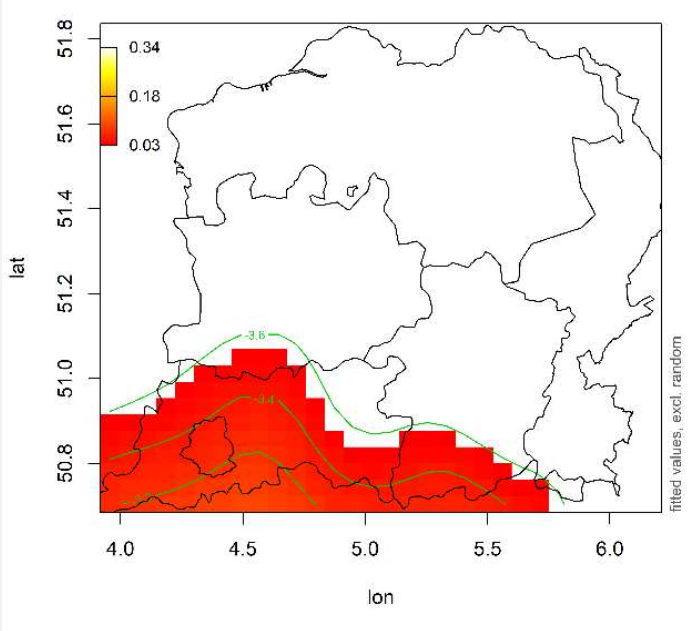

Figure 3b: French tokens per location (personality \& feelings)

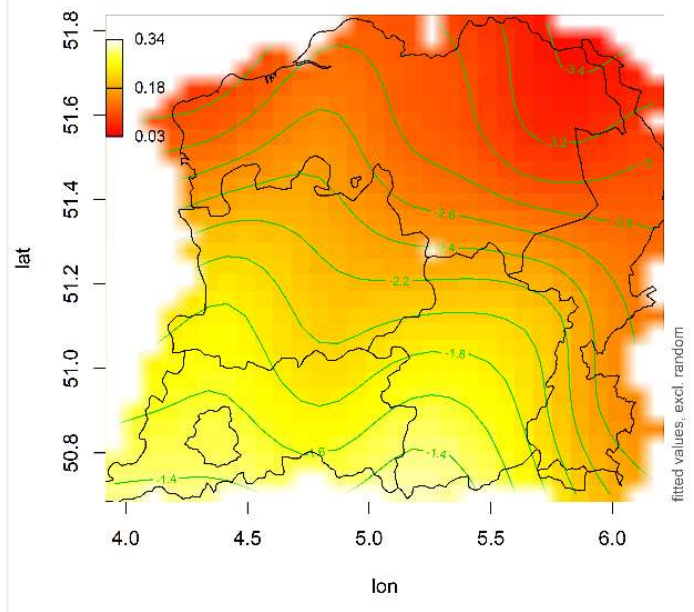

Figure 3d: French tokens per location (clothing \& personal hygiene) 


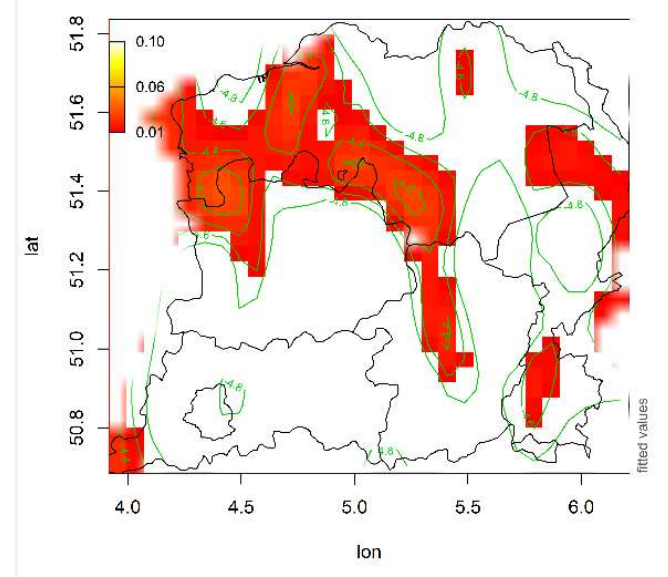

Figure 4a: Latin tokens per location (society, school \& education)

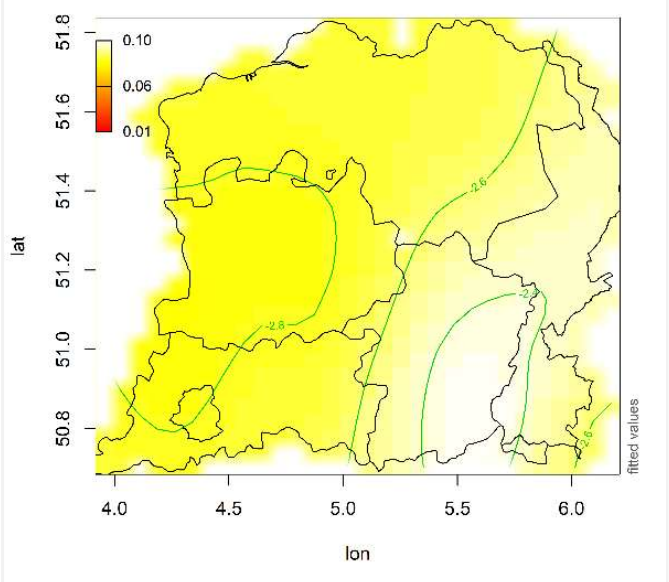

Figure 4c: Latin tokens per location (church \& religion)

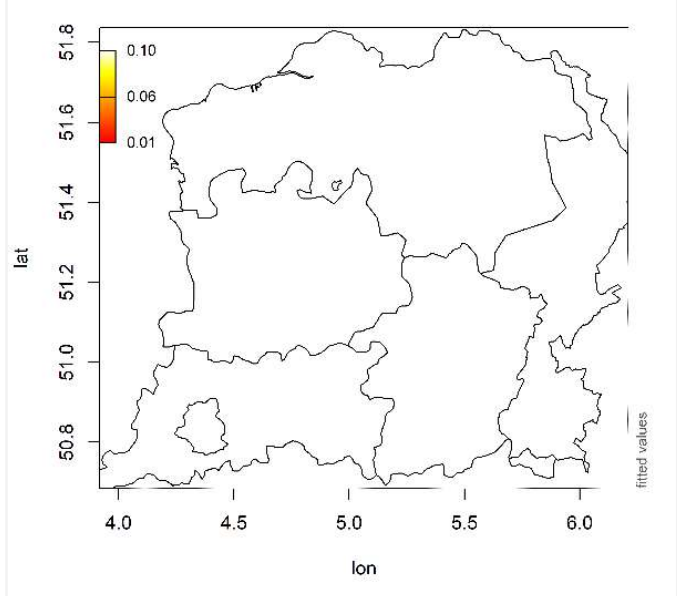

Figure 4b: Latin tokens per location

(personality \& feelings)

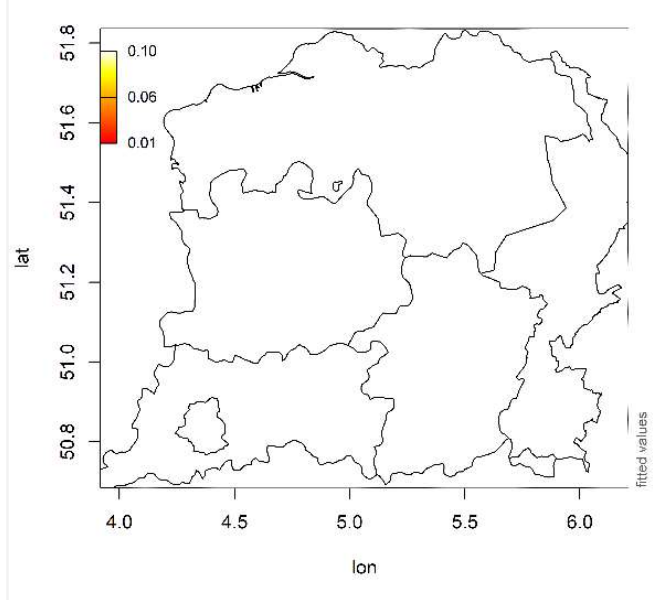

Figure 4d: Latin tokens per location (clothing \& personal hygiene) 
Maps, meanings and loanwords 49

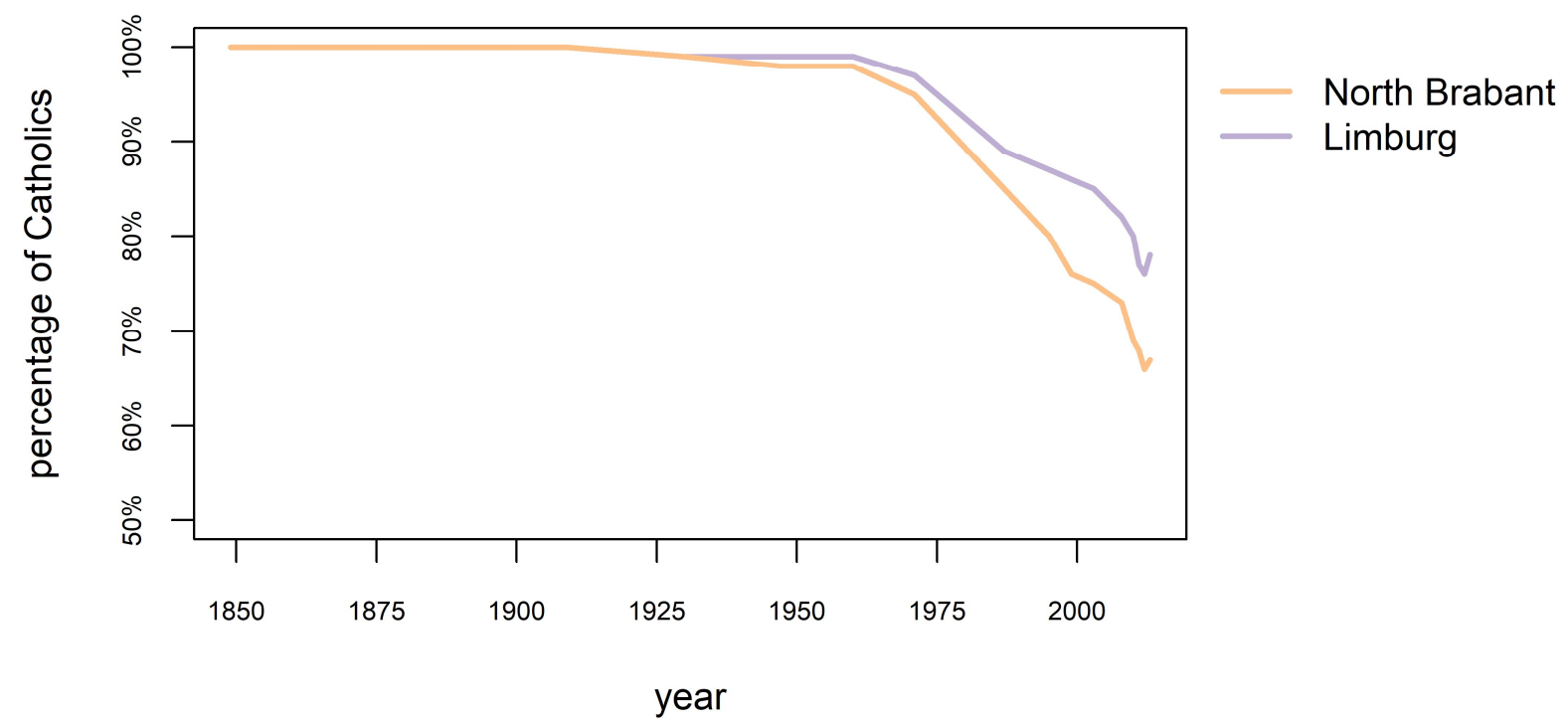

Figure 5: Percentage of (self-reported) Catholics in the provinces of North Brabant and Limburg in the Netherlands from 1849 until 2013 (Schmeets, 2014: 6) 


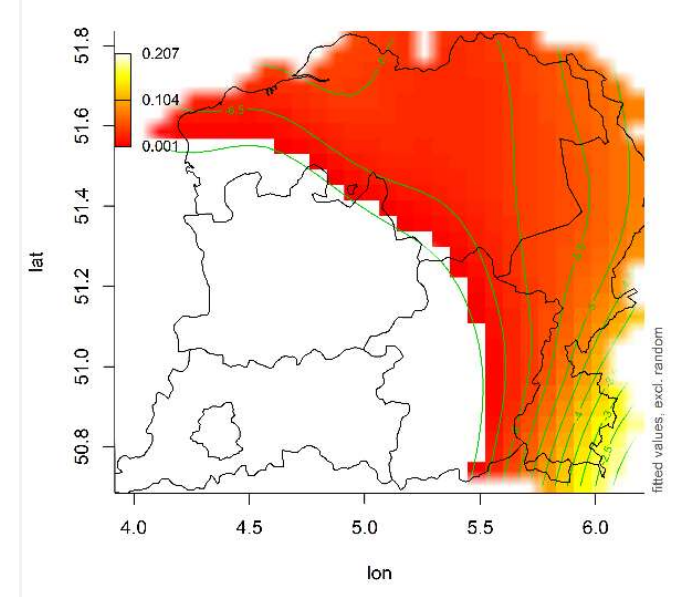

Figure 6a: German tokens per location (society, school \& education)

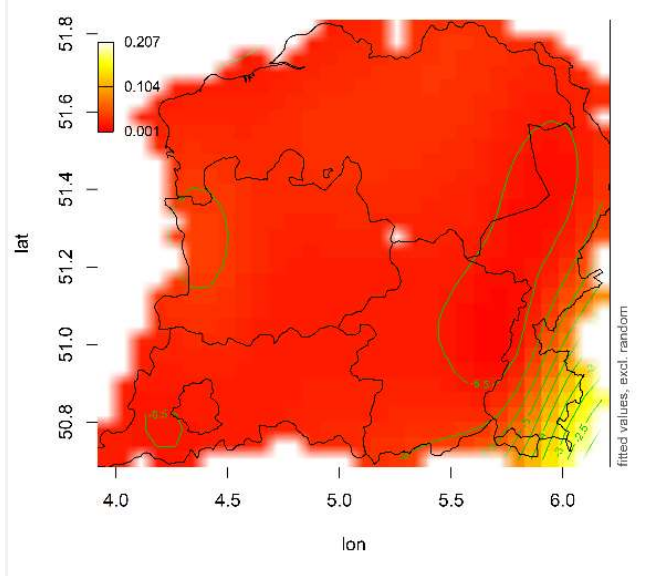

Figure 6c: German tokens per location (church \& religion)

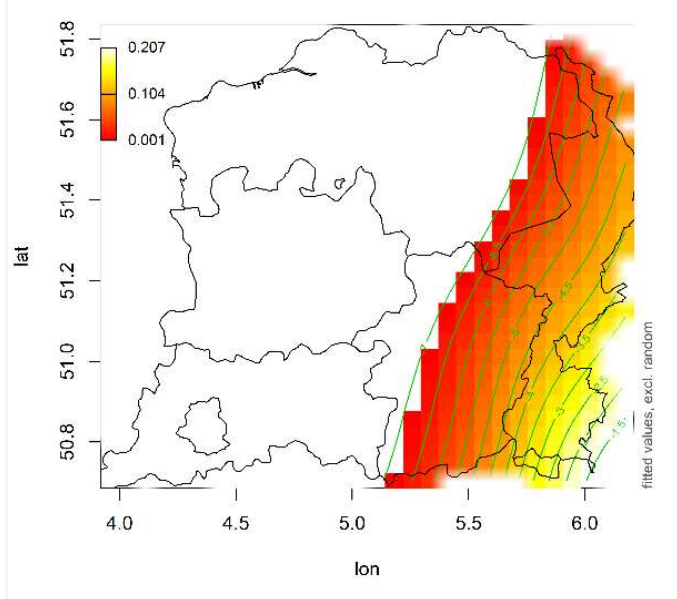

Figure 6b: German tokens per location (personality \& feelings)

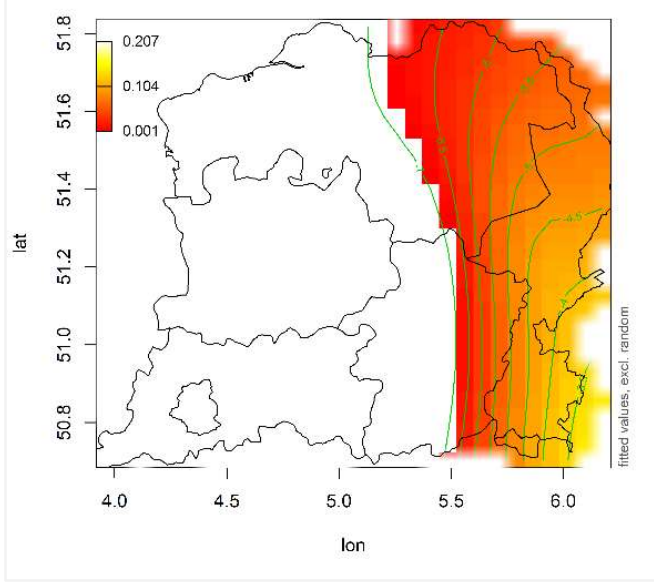

Figure 6d: German tokens per location (clothing \& personal hygiene) 


\section{Appendix 1: Output of the GA(M)Ms}

A. Numerical output of the GAMM for French loanwords

\begin{tabular}{|c|c|c|c|c|}
\hline \multicolumn{5}{|l|}{ parametric coefficients } \\
\hline & & estimate & $\mathrm{SE}$ & p-value \\
\hline \multicolumn{2}{|l|}{ Intercept } & -3.030 & 0.017 & $<0.001$ \\
\hline \multicolumn{2}{|c|}{ semantic field (personality \& feelings) } & -1.187 & 0.028 & $<0.001$ \\
\hline \multicolumn{2}{|c|}{ semantic field (church \& religion) } & -0.164 & 0.021 & $<0.001$ \\
\hline \multicolumn{2}{|c|}{ semantic field (clothing \& hygiene) } & 0.740 & 0.018 & $<0.001$ \\
\hline \multicolumn{5}{|c|}{ approximate significance of smooth terms } \\
\hline \multicolumn{2}{|c|}{ 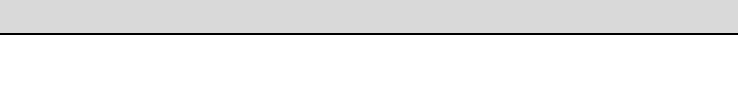 } & edf & \multicolumn{2}{|r|}{ p-value } \\
\hline \multicolumn{2}{|c|}{$\begin{array}{l}\text { s(lon, lat) : sem. field (society, school \& } \\
\text { education) }\end{array}$} & 24.85 & \multicolumn{2}{|r|}{$<0.001$} \\
\hline \multicolumn{2}{|c|}{ s(lon, lat) : sem. field (personality \& feelings) } & 18.03 & \multicolumn{2}{|r|}{$<0.001$} \\
\hline \multicolumn{2}{|c|}{$\mathrm{s}$ (lon, lat) : sem. field (church \& religion) } & 3.83 & \multicolumn{2}{|r|}{$<0.001$} \\
\hline \multicolumn{2}{|c|}{$\mathrm{s}$ (lon, lat) : sem. field (clothing \& hygiene) } & 21.96 & \multicolumn{2}{|r|}{$<0.001$} \\
\hline \multicolumn{2}{|l|}{ s(location) } & 329.29 & \multicolumn{2}{|r|}{$<0.001$} \\
\hline \multicolumn{5}{|l|}{ explanatory power } \\
\hline null deviance explained & \multicolumn{4}{|l|}{$92 \%$} \\
\hline adjusted $\mathrm{R}^{2}$ & \multicolumn{4}{|l|}{0.908} \\
\hline
\end{tabular}


B. Numerical output of the GAM for Latin loanwords

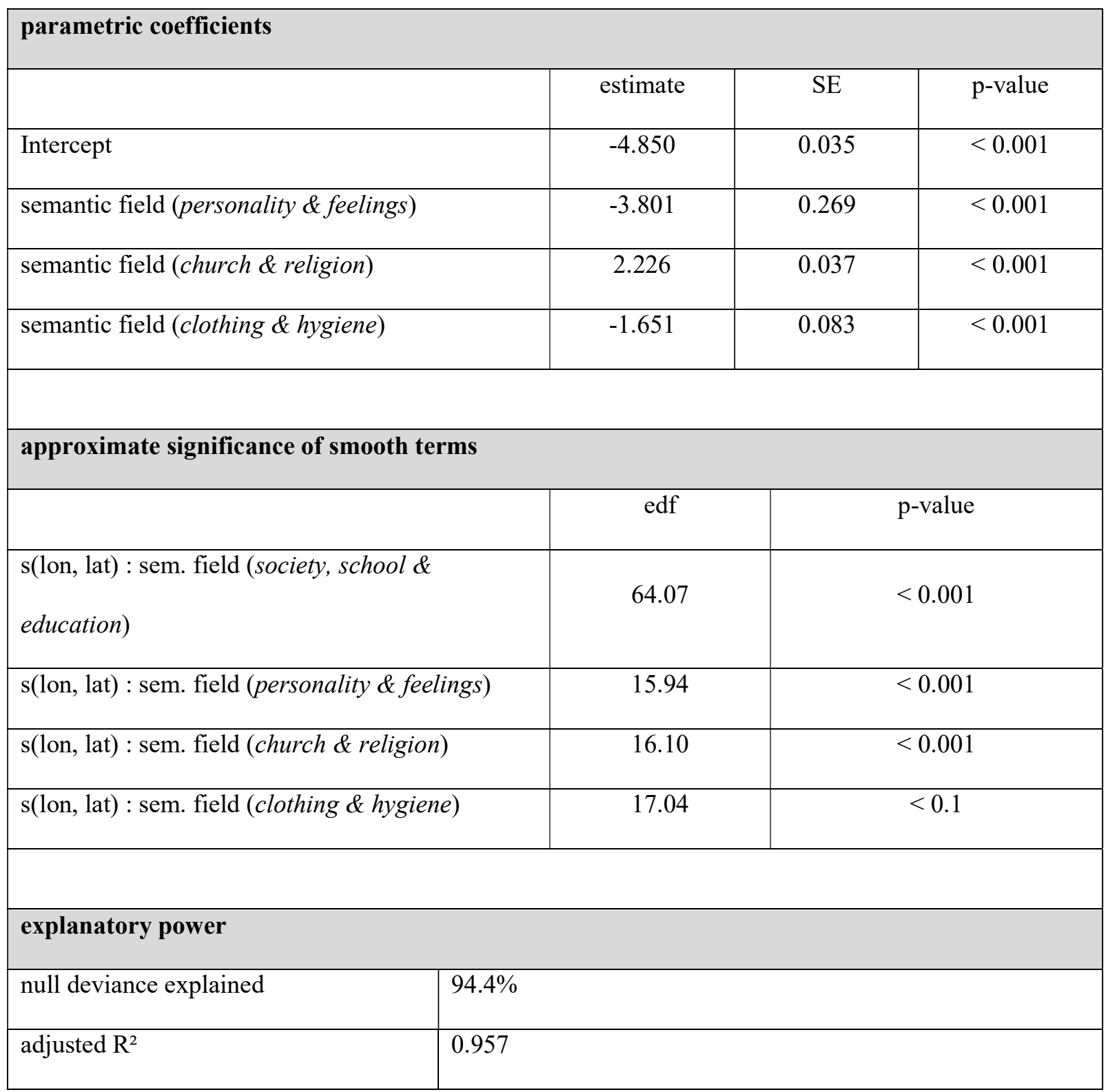


C. Numerical output of the GAMM for German loanwords

\begin{tabular}{|c|c|c|c|c|}
\hline \multicolumn{5}{|l|}{ parametric coefficients } \\
\hline & & estimate & SE & p-value \\
\hline \multicolumn{2}{|l|}{ intercept } & -6.879 & 0.171 & $<0.001$ \\
\hline \multicolumn{2}{|c|}{ semantic field (personality \& feelings) } & -0.116 & 0.244 & 0.634 \\
\hline \multicolumn{2}{|c|}{ semantic field (church \& religion) } & 0.714 & 0.184 & $<0.001$ \\
\hline \multicolumn{2}{|c|}{ semantic field (clothing \& hygiene) } & -0.027 & 0.222 & 0.902 \\
\hline \multicolumn{5}{|c|}{ approximate significance of smooth terms } \\
\hline \multicolumn{2}{|c|}{ 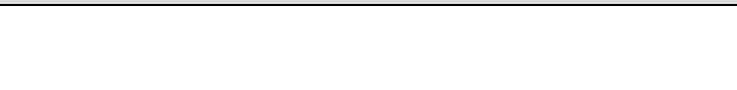 } & edf & \multicolumn{2}{|r|}{ p-value } \\
\hline \multicolumn{2}{|c|}{$\begin{array}{l}\mathrm{s}(\text { lon, lat) : sem. field (society, school \& } \\
\text { education) }\end{array}$} & 13.91 & \multicolumn{2}{|r|}{$<0.001$} \\
\hline \multicolumn{2}{|c|}{ s(lon, lat) : sem. field (personality \& feelings) } & 11.58 & \multicolumn{2}{|r|}{$<0.001$} \\
\hline \multicolumn{2}{|c|}{$\mathrm{s}$ (lon, lat) : sem. field (church \& religion) } & 14.61 & \multicolumn{2}{|r|}{$<0.001$} \\
\hline \multicolumn{2}{|c|}{$\mathrm{s}$ (lon, lat) : sem. field (clothing \& hygiene) } & 12.50 & \multicolumn{2}{|r|}{$<0.001$} \\
\hline \multicolumn{2}{|l|}{ s(location) } & 59.72 & \multicolumn{2}{|r|}{$<0.001$} \\
\hline \multicolumn{5}{|l|}{ explanatory power } \\
\hline null deviance explained & \multicolumn{4}{|l|}{$89.2 \%$} \\
\hline adjusted $\mathrm{R}^{2}$ & \multicolumn{4}{|l|}{0.928} \\
\hline
\end{tabular}


Appendix 2: Distribution of "German" concepts that occur in at least two locations in the Ripuarian dialect area in the semantic field of Personality and feelings

[cf. separate file: appendix2_german_concepts_ripuarian_dialects.xlsx] 